\title{
Calibration of the Sonseca Array with Large Magnitude Regional and Teleseismic Events
}

\section{RECEIVED

\section{Farid U. Dowla}

Geophysics and Global Security Department Lawrence Livermore National Laboratory

\section{July 1996}

This is an informal report intended primarily for internal or limited external distribution. The opinions and conclusions stated are those of the author and may or may not be those of the Laboratory.

Work performed under the auspices of the U.S. Department of Energy by the Lawrence Livermore National Laboratory under Contract W-7405-Eng-48. 


\section{DISCLAIMER}

Portions of this document may be illegible in electronic image products. Images are produced from the best available original document. 


\title{
Calibration of the Sonseca Array with Large Magnitude Regional and Teleseismic Events
}

\author{
Farid U. Dowla
}

Geophysics and Global Security Department

Lawrence Livermore National Laboratory

July 1996 


\title{
Calibration of the Sonseca Array with Large Magnitude Regional and Teleseismic Events
}

\author{
Farid U. Dowla
}

\begin{abstract}
In order to calibrate the Sonseca station, a 19-element short-period seismic array with a $9 \mathrm{~km}$ diameter circular aperture located in central Spain $(39.68 \mathrm{~N}, 3.96 \mathrm{~W})$, wavefield measurements made on observed seismic phases are compared with expected values. Thirty-five well-recorded regional and teleseismic events are used to study bearing and phase velocity estimation properties. Preliminary results indicate that in general the Sonseca array performs well for both regional and teleseismic events for frequencies less than $5 \mathrm{~Hz}$ using standard array signal processing techniques. Main findings of this study are: (i) A systematic bias is observed in bearing estimates; the bias is a function of the true bearing for events from the easterly directions of the array and can be mitigated with a simple bias correction. Using a least-squares quadratic polynomial fit, the bearing estimation error can be reduced to less than two or three degrees. (ii) Measured signal and noise coherence functions and beamforming suggest that for regional events improved SNR is obtained by beamforming in the frequency band of 0.5 to $4 \mathrm{~Hz}$ with a resulting array gain as high as $10 \mathrm{~dB}$. (iii) Because the element spacing of Sonseca array corresponds to that of a sparse regional array, spatial aliasing can be observed in narrowband $\mathrm{f}-\mathrm{K}$ analysis at the higher frequencies. We compare performance of narrowband and broadband frequency-wavenumber (f-k) analysis and suggest preliminary recipes for $f-k$ and beamforming analysis.
\end{abstract}

\section{INTRODUCTION}

We begin with a brief discussion of the sensor array geometry and the data that were used to conduct this study. In section II performance of the array in terms of measuring characteristics of the seismic wavefield is discussed. Bearing and phase velocity estimation properties of the array is shown to be quite good in the 1 to $2 \mathrm{~Hz}$ frequency band. In section III we consider the issue of array coherence, a property that can make a significant difference in beamforming for identification of primary and secondary phases. Even for frequencies as high as $1.75 \mathrm{~Hz}$, the coherence characteristics of the array is found to be high over the full array aperture. Resolution and spatial aliasing properties of the array are discussed in section IV. Because the array is a relatively sparse one, spatial aliasing can be a problem with narrowband $\mathrm{f}-\mathrm{k}$ analysis at frequencies greater than $5 \mathrm{~Hz}$. We demonstrate, with an example, the need for a more dense array to handle higher frequencies. For low magnitude events, the use of higher frequencies might be quite important for improved array gain.

\subsection{The Sonseca Array}

The Sonseca array is located in a relatively flat region in central Spain (see Figure 1). The short-period array with 19- or 20- elements approximately outlines the shape of the two 
chambers of the human heart (see Figure 2) and has an aperture of about $9 \mathrm{~km}$. The sampling rate of the data is $20 \mathrm{~Hz}$. The elements of the array are placed fairly far apart from each other when compared to other regional arrays such as the Noress in Norway. Note that the long period instruments of Sonseca that surrounds the denser short period array (see Figure 3) were not used in this study. This study was restricted to the use of short-period sensors.

\subsection{Calibration Events}

The set of seismic events that were used in this study are shown in Table 1. For all these events at least 19 of the array elements had well recorded data. Our initial set of about a hundred or so events eventually reduced to only 35 events, ones that were essentially free of significant data glitches and dropouts. A map of the events is shown in Figure 4. Histograms of magnitude, bearings, and distances of the events are shown in Figure 5. For the events in the data set used, bearing coverage was from 78 to 183 degrees, and event distances varied from 330 to $5829 \mathrm{~km}$, with 13 events at distances less than $2000 \mathrm{~km}$. The magnitudes varied from 4.5 to $6.2 \mathrm{mb}$. In summary, the results of this study are based on a set of fairly large magnitude regional and teleseismic events and from a limited range in azimuths.

\section{ARRAY PERFORMANCE}

An example Sonseca data set as shown in Figure 6 corresponds to an event $478 \mathrm{~km}$ from the array and at a bearing of 181 degrees. The broadband $\mathrm{f}-\mathrm{k}$ spectrum (see Figure 7) on the Pn phase for this event produces a bearing error of less than a one degree. While the array measurements for this particular event is excellent, a goal of this study is to understand the error statistics of the array performance. The first part of the study focused on understanding the bearing and phase velocity estimation capabilities of the array on a relatively large number of fairly well-recorded high SNR regional and teleseismic events. The first task was to identify the P and S (or Pn and Sn) arrivals for the given set of events. Using group velocity measurements, IASPEI travel times, and by making a number of other measurements, the arrivals times of the phases were carefully identified by analysts in all these events. A pre-event noise window was also identified. The arrival time picks made by the analyst were to used define analysis windows in the data. Measurements such as bearing, phase velocity, and signal and noise coherence using a $15 \mathrm{~s}$ window were then made of the phases. Although a $15 \mathrm{~s}$ window might be considered too long in some applications, we found that this was a good design choice for obtaining stable estimates. The bearing and phase velocity estimation results are discussed in this section. In section II, we discuss the signal and noise coherence properties of the array.

Since the location of the events were known from the published Preliminary Determination of Epicenter (PDE) bulletins, we were able to study the bearing estimation performance of the array. In general, the bearing estimation properties of Sonseca array are quite good. For events between 110 and 183 degrees, the broadband $\mathrm{f}-\mathrm{k}$ analysis in the 1 to $2 \mathrm{~Hz}$ frequency range produces an error mean and standard deviation of 1.3 and 2.3 degrees, respectively.

The results of the bearing estimation performance on the $\mathrm{Pn}$ and $\mathrm{P}$ are summarized in Figures 8 a. There seems to be a systematic bias in bearing estimation for events from a direction between 78 and 100 degrees (see top of Figures 8-a). The apparent event bearing seems to be less than the true bearing. In other words, the wavefield is being refracted anticlockwise.

To see the utility of a simple bias correction on bearing error, a least squares quadratic polynomial was used to remove the bias as a function of the estimated bearing. In other words we made a simple bias correction on the apparent bearing measured by the array. This procedure was quite useful as it reduced the error mean and standard deviation from (- 
$5.87,5.43)$ to $(0.0,2.54)$ degrees. Indeed the same trend is observed in the other frequency bands. In Figure 8-b, results for the 2 to $3 \mathrm{~Hz}$ analysis band are summarized.

We have also compared the performance of the SAC broadband $\mathrm{f}-\mathrm{k}$ analysis with the Geotool's narrowband $\mathrm{f}-\mathrm{k}$ analysis for many different frequency bands. The performance of the two algorithms are quite comparable except at the frequencies greater than about $5 \mathrm{~Hz}$. Figures 9 a-b summarize the results of narrowband analysis. For frequencies greater than 5 $\mathrm{Hz}$ it was observed that spatial aliasing can be a serious problem with narrowband $\mathrm{f}-\mathrm{k}$ analysis, especially with short duration analysis windows. We discuss the spatial aliasing properties of the Sonseca array in greater detail in section IV.

Since 13 of the 35 events were regional (less than $2000 \mathrm{~km}$ away from the array), we were able to compare the bearing of the Pn and $\mathrm{Sn}$ phases (see Figure 10). From the results shown we conclude that for regional events, the $\mathrm{Sn}$ bearing is as good as the $\mathrm{Pn}$ bearing for frequencies in the range 0.5 to $2 \mathrm{~Hz}$.

\subsection{Phase Velocity Estimation}

The results of the phase velocity measurement on the $\mathrm{Pn}$ and $\mathrm{P}$ phases are summarized in Figure 11. We compare these phase velocities with those derived from the IASPEI travel times for sources at the surface and at a depth of $33 \mathrm{~km}$. In the comparison shown in Figure 11, velocity estimates at a number of different frequencies between 1 and 4.5 $\mathrm{Hz}$ are plotted. Furthermore, for small magnitude regional events it might be possible to use primary and secondary phases to determine event location.

A comparison of the $\mathrm{Pn}$ and the $\mathrm{Sn}$ velocities for the regional events are shown in Figure 12. Results indicate that the phase velocities, because they are so different for regional phases, can be used in event phase identification tasks. For the most part there seems to be a good agreement between the theoretical and the empirical results and this leads to conclude that phase velocity could be used to differentiate the primary and secondary phases at Sonseca.

\section{ARRAY GAIN}

\subsection{Coherence Analysis}

A fundamental assumption in array signal processing is that the signal is coherent and the noise incoherent over the entire array. Measuring the correlation of the signals as a function frequency and spatial lag (i.e. determining the spatial coherence function of the seismic wavefield in the planar array) can be quite useful in understanding the array performance and for developing beamforming algorithms with improved array gain.

There are number of different approaches (Mykkelveit and Ringdal, 1981) for estimating the signal and noise coherence function for an array; as to which is the best approach the question is still open to debate. The problem is complicated both by presence of noise in the signal, and by the presence of signals in the noise. To estimate the coherence function we first filtered data with $1 \mathrm{~Hz}$ bandpass filters with different center frequencies. For each frequency band, the normalized cross-correlation functions were then computed for every pair of sensors in the array. With 20 sensors over a non-uniform grid, there are 190 distinct pairs or spatial lags in coherence function. The maximum of the normalized crosscorrelation function was then averaged over all 35 events to obtain an estimate of the coherence function at that spatial lag and for that temporal frequency. Spatial averaging of the coherence function was then employed to further reduce the variance of these estimates. In this algorithm, by using the maximum of the cross-correlation function we essentially remove the propagation delay between the sensor pairs. We use an identical set of operations to compute the coherence of pre-event noise. Mathematically the algorithm described above is given by: 


$$
C(z, f)=\int_{\text {Space } z \pm \Delta z} d z \sum_{\text {Events }} \max _{\tau}\left[\frac{1}{2 T} \int_{-T}^{T} d t s\left(t: f \pm \Delta f, x_{1}, y_{1}\right) s\left(t-\tau: f \pm \Delta f, x_{2}, y_{2}\right)\right]
$$

where,

$z=\sqrt{\left(x_{1}-x_{2}\right)^{2}+\left(y_{1}-y_{2}\right)^{2}}$

Note in the above $f$ represent frequency, $t$ time, $z$ spatial lag, and $s(t: f, x, y)$ the normalized bandpass signal at the array location $(x, y)$. The coherence results are summarized in Figure 13 a-d. The method used might be considered an upper bound for noise correlation as the maximum in the correlation function will tend to inflate noise coherence. One notable observation is that the array maintains good coherence even at $1.75 \mathrm{~Hz}$ for a spatial lag of 8 $\mathrm{km}$. Simply by looking at the decay rate and separation of the signal and noise coherence functions, it would appear that the frequency range from 0.5 to $3.5 \mathrm{~Hz}$ would result in good array signal processing performance. The results of bearing and phase velocity estimation do agree with this conclusion. Implications in terms of the array gain and beamforming is discussed next.

\subsection{Beamforming and Array Gain}

We have observed that standard time domain beamforming can be highly effective in suppressing noise and in bringing out the various phases in the data. By using the empirical phase velocity and bearing estimates to compute the beams, we were able to significantly improve the SNR of the data. Preliminary observations indicate that the P or Pn beams in the 0.5 to $4.5 \mathrm{~Hz}$ range might be useful for accurate determination of the first arrival onset times. Results of travel time analysis will be summarized in our next report.

Since the signal coherence at large spatial lags usually degrades with frequency above $4 \mathrm{~Hz}$, beamforming algorithms that divides the array into subarrays and then use the various subarrays to form beams at different frequencies is a method that we are currently working on. Results (see Figure 14) using a simple filterbank technique did not produce significantly different beams with our initial attempt at subarray beamforming. The use of wavelet decomposition with exact or perfect reconstruction properties and the combination of the beams of different scales and on different subarrays might be a good way to solve this problem.

Array gain is the ratio of the output SNR to the input SNR. With the beams already computed we can estimate the array gain by:

$$
\text { Array Gain }=\frac{\int p_{t} p_{\text {beam }}^{2}(t) d t / \int_{t} n_{\text {beam }}^{2}(t) d t}{\frac{1}{N} \sum_{k=1}^{N} \int_{t} p_{k}{ }^{2}(t) d t / \int n_{l}{ }^{2}(t) d t}
$$

where $p_{k}(t)$ represents the P-wave segment and $n_{k}(t)$ represents the pre-event noise segment of the kth channel for the $\mathrm{N}$ element array. Since array gain is usually a function of frequency, we measured the array gain in the 1 to $2 \mathrm{~Hz}$ band by filtering the signal. The ratio of the beam SNR is then compared to the SNR of the array center station. Another approach would be to use the average of all the individual stations. The center station was found to be one of the most stable stations of the array. The results of the array gain for the events are given in Table 2 . An array gain of $8 \mathrm{~dB}$ array gain is not unusual in the $1 \mathrm{Ho} 2 \mathrm{~Hz}$ frequency band. We note also that the array gain measured for the different events is a function of the event SNR. 


\section{ARRAY RESOLUTION AND SPATIAL ALIASING}

\subsection{Beampattern}

Since the Sonseca is not a perfectly symmetric array we computed the beampattern of the array at different directions. As shown in Figures 15 and 16, the sidelobes for the direction 180 degrees is quite different from the sidelobes for the direction 45 degrees. The beampattern in the 180 degree direction suggests that spatial aliasing can be a problem for the array for events from this direction. Because problems due to spatial aliasing is independent of SNR, high frequency narrowband analysis should be avoided on a Sonseca type array. Array signal processing methods will benefit for sidelobe suppression techniques such as adaptive sub-array spatial processing algorithms.

\subsection{Aliasing: Narrowband versus Broadband $\mathrm{f}-\mathrm{k}$ Analysis}

An idea of the spatial aliasing characteristics of the array can be obtained by computing the coarray distances of the array. As shown in Figure 17, the minimum separation of the array elements is $0.73 \mathrm{~km}$, the array aperture is $9.57 \mathrm{~km}$ and the median separation between the stations is $4.13 \mathrm{~km}$. Furthermore there are only three sensors separated by less than $1.25 \mathrm{~km}$. At frequency $6 \mathrm{~Hz}$, a wavefield with phase velocity $6 \mathrm{~km} / \mathrm{s}$ has a wavelength of $1 \mathrm{~km}$. From the sampling theorem viewpoint, minimum separation between the elements should be $0.5 \mathrm{~km}$. Hence, from this simple analysis we can conclude that the Sonseca array with its present design might be highly prone to spatial aliasing, especially with narrowband high frequency analysis. We have observed a possible evidence of spatial aliasing with narrowband analysis for the event corresponding to Figures 6 and 7 . As shown in Figures 18, while narrowband $\mathrm{f}-\mathrm{k}$ analysis on the Pn phase produces expected bearing and velocity results (see Figure 18-a) of narrowband f-k analysis in the 4.75 to 5.75 $\mathrm{Hz}$ band produces unacceptable aliasing (see Figure 18-b). In this example we used a $4 \mathrm{~s}$ analysis window. The aliasing in $\mathrm{f}-\mathrm{k}$ analysis is rather disturbing because the peak of the signal spectrum for this event is around $5.25 \mathrm{~Hz}$.

\section{SUMMARY AND RECOMMENDATIONS}

Performance of the Sonseca array was studied with a set of 13 regional and 22 teleseismic events. On the whole the performance of the array for bearing and velocity estimation seems to be quite good for frequencies less than $5 \mathrm{~Hz}$. However, the array is unable to handle narrowband high frequency analysis. As low magnitude regional or local events might have to be processed at higher frequencies, it might be useful to populate the Sonseca type arrays with a few more stations.

Because of its large aperture, the array has good bearing resolution properties and the coherence of the signal is quite good even at a spatial lag of $8 \mathrm{~km}$ at $1.75 \mathrm{~Hz}$. Because of good signal coherence, the array gain could be as high as $10 \mathrm{~dB}$ with excellent bearing and velocity resolution.

We observed a systematic bias in bearing for events from the direction 78 to 100 degrees. However, a simple quadratic polynomial fit calibration technique can be used to reduce the bias in the estimate. We also observed that accuracy in the Sn bearing seems to be as good as that of the $\mathrm{Pn}$ in the 0.5 to $2 \mathrm{~Hz}$ band.

Other observations made in this preliminary study certainly warrant further work. Finally, because of its large aperture, subarray wavelet decomposition based beamforming algorithms might allow use of the high frequency components of the recorded data. 


\section{ACKNOWLEDGMENTS}

I would like to thank Dave Harris and Fred Followill for comments on the first draft of this report. Discussions with Howard Patton and Flori Ryall on phase identification, with Craig Schultz on IASPEI models and phase velocity travel times, and with Dave Harris on array coherence estimation are gratefully acknowledged. Thanks are also due to Terri Hauk and Steve Jarpe for the organizational aspects of the data; to Peter Goldstein for SAC and to John Coyne for Geotool, seismic analysis codes that were used in this study; and to Carolyn. Bailey and Stan Ruppert for system development and maintenance. We thank AFTAC for providing the data and thus allowing us to carry out this study. This work was performed under the auspices of the U.S. Department of Energy by Lawrence Livermore National Laboratory under contract W-7405-Eng-48.

\section{REFERENCES}

Mykkeltveit, S. and F. Ringdal. (1981). Phase identification and event location at regional distance using small aperture array data. E. S. Husebye and S. Mykkeltveit (eds.), Identification of Seismic Sources - Earthquake or Underground Explosions, D. Reidel Publishing Company, Holland, 1981.

\section{FIGURE CAPTIONS}

Figure 1: The location of the Sonseca Array in a relatively flat region in central Spain.

Figure 2: The nineteen short-period station of the Sonseca array approximately outline the shape of the two chambers of the human heart. The array has aperture of approximately 9 kilometers.

Figure 3: The outer long-period station were not used in this study, but are useful in capturing the secondary arrivals of teleseismic events.

Figure 4: A map of the events that were used to conduct this study.

Figure 5: Histograms of the parameters (magnitude, distance, and backazimuth) of the events.

Figure 6: A typical array data set. This particular event corresponds to a 5.2 magnitude earthquake at a distant of $478 \mathrm{~km}$ from the array center, and at a bearing of 181 degrees. The depth of the event is $10 \mathrm{~km}$.

Figure 7: The broadband f-k spectrum on the Pn segment for the event described in Figure 6.

Figure 8-a: Performance of the array of broadband bearing estimation in the frequency band 1-2 $\mathrm{Hz}$.

Figure 8-b: Performance of the array of broadband bearing estimation in the frequency band $2-3 \mathrm{~Hz}$. 
Figure 9-a: : Performance of the array of narrowband bearing estimation in the frequency band $1-2 \mathrm{~Hz}$.

Figure 9-b: Performance of the array of narrowband bearing estimation in the frequency band $2-3 \mathrm{~Hz}$.

Figure 10: Comparison of bearing estimation between the $\mathrm{Pn}$ and $\mathrm{Sn}$ regional phases. The error (mean, standard deviation) are depicted inside the parenthesis of the figure legend.

Figure 11: The measured $\mathrm{P}$ and $\mathrm{Pn}$ phase velocity at various frequency bands compares approximately well with the theoretical IASPEI travel time curves. Note the curious observation that there is a downward slope in the phase velocity versus distance plot for events less than $1000 \mathrm{~km}$ away.

Figure 12: A comparison of the $\mathrm{Pn}$ and $\mathrm{Sn}$ phase velocities as a function of event distance. A somewhat interesting observation is that the observed phase velocities for both phases tend decrease slightly with distance for regional distances. Note, there seems to be a definite relationship between $\mathrm{Pn}$ and $\mathrm{Sn}$ phase velocities for these events.

Figure 13 a-d: Signal and noise coherence as a function of sensor separation and frequency. Note best separation of signal and noise occurs in the 0.75 to $2.5 \mathrm{~Hz}$ range. The signal coherence curve is indicated by " $O$ " and the noise coherence by "X." As pointed out in the text, the use of the maximum value of the noise cross-correlation function might result in somewhat inflating the measured noise coherence value.

Figure 14: Results indicate beamforming will significantly improve the SNR. The top trace corresponds to unprocessed sensor data, the middle trace represents output of the standard beamforming algorithm, and the bottom trace corresponds to output of subarray beamforming. Standard beamforming can result in $10 \mathrm{~dB}$ array gain, depending on the sensor SNR. The subarray beamforming was performed by combining beams at different frequencies with subarray aperture determined by the highest frequency. As is evident, use of simple bandpass filterbanks do result in a significantly different result. It is anticipated that the use of wavelet scale decomposition night be more useful.

Figure 15: The beampattern of the Sonseca array in the direction 180 degrees backazimuth. Note the strong sidelobes in the beampattern suggests that for events from the 180 degrees direction and for higher frequencies, aliasing in the $\mathrm{f}-\mathrm{k}$ spectra is a possibility.

Figure 16: The beampattern of the Sonseca array in the direction 45 degrees backazimuth.

Figure 17: The distribution of the coarray separation of the Sonseca array.

Figure 18-a: Narrowband f-k spectrum in the $3 \mathrm{~Hz}$ frequency band.

Figure 18-b: Narrowband $\mathrm{f}-\mathrm{k}$ spectrum in the $5.25 \mathrm{~Hz}$ frequency band. The signal spectrum peaks at around $5.25 \mathrm{~Hz}$. Note that aliasing can be significant problem in narrowband $\mathrm{f}-\mathrm{k}$ analysis.

\section{TABLE CAPTIONS}

Table 1: Seismic events used in this study. The data are obtained from the PDE seismic bulletin.

Table 2: Broadband array gain due to time-domain beamforming. 
Table 1: Event Bulletin

\begin{tabular}{|c|c|c|c|c|}
\hline id & lat & lon & depu & may \\
\hline 9107018.3 .343 & 37.009 & 30.989 & 113 & 5.1 \\
\hline 91205094541 & 36.520 & $44.0 \mathrm{~K} 63$ & 26 & 5.4 \\
\hline 91220224610 & 35.629 & 11.657 & 32 & 4.8 \\
\hline 92164791643 & 34.159 & 8.3 .33 & 10 & 5.7 \\
\hline 92273150408 & 34.478 & 14,483 & 10 & 4.7 \\
\hline 92286130955 & 29.778 & 31.14 & 22 & 5.9 \\
\hline 92297091109 & 31.355 & -4.318 & 29 & 5.3 \\
\hline 92304104358 & 31.284 & +372 & 26 & 5.1 \\
\hline 93143074056 & 35.357 & $-2.5 \% 2$ & 27 & 5.4 \\
\hline 93195123149 & 38,224 & 21.756 & 23 & 5.3 \\
\hline 93196052405 & 36.407 & 9.329 & 10 & 4.5 \\
\hline 93213002040 & 15.385 & 31.690 & 13 & 5.2 \\
\hline 93215124305 & $2 \times, 729$ & 34.553 & 10 & 5.9 \\
\hline 93215163320 & 28.777 & 34.668 & 10 & 5.6 \\
\hline 93253153947 & 34.834 & 12.441 & 10 & 4.7 \\
\hline 93253160232 & 35.039 & 12.366 & 10 & 5.0 \\
\hline 93308051837 & 38.372 & 22.002 & 17 & 50 \\
\hline 433.5714ברב3.5 & 36.756 & -2.937 & 27 & 5.0 \\
\hline 94005132409 & 39.085 & 15.145 & 273 & 5.7 \\
\hline 94028154524 & 38.693 & 27.493 & 5 & $5 . ?$ \\
\hline 94054080204 & 30.853 & 60.590 & 6 & 6.1 \\
\hline $940560 \geq 3051$ & 38.854 & 20.532 & 36 & 5.3 \\
\hline 9410623093,3 & 37.4 .30 & 20.637 & $2 \pi$ & 5.3 \\
\hline 94143064616 & 35.559 & 24.727 & 76 & 6.0 \\
\hline $9414+020536$ & 38.664 & $26.54 ?$ & 17 & 5.0 \\
\hline 94146082652 & 35.305 & -4.103 & 10 & 5.7 \\
\hline 94317065600 & 36.910 & 29.650 & 10 & 4.9 \\
\hline 94324143102 & 35.335 & 39.557 & 29 & 5.1 \\
\hline 94,333143028 & 38.707 & 20.484 & 21 & 4.9 \\
\hline 95124003409 & 40.572 & 23.617 & 10 & 5.1 \\
\hline 95133084712 & 40.149 & 21.695 & 14 & 6.2 \\
\hline 95135041355 & 40.034 & 21.655 & 14 & 5.2 \\
\hline 951390648449 & 40.073 & 21.564 & 10 & $\$ .1$ \\
\hline $951+4045832$ & 35.039 & 32.246 & 10 & 5.3 \\
\hline 95265112010 & 35.325 & 8.249 & 10 & 4.7 \\
\hline
\end{tabular}


Table 2: Broadband Array Gain

\begin{tabular}{|c|c|c|}
\hline Event-ID & Gain & dB.Gain \\
\hline 1 & $4.551 \mathrm{e}+00$ & 3 \\
\hline 2 & $4.222 \mathrm{e}+00$ & 6 \\
\hline 3 & $5.555 e+00$ & 7 \\
\hline 4 & $5.745 \mathrm{e}+(\mathrm{M})$ & 8 \\
\hline 5 & $8.420 e+(0)$ & 9 \\
\hline 6 & $5.968 \mathrm{e}+00$ & 8 \\
\hline 7 & $9.502 \mathrm{e}+00$ & 10 \\
\hline 8 & $5.774 \mathrm{e}+(\mathrm{M})$ & 8 \\
\hline 9 & $1.009 \mathrm{e}+01$ & 10 \\
\hline 10 & $3.129 \mathrm{e}+00$ & 5 \\
\hline 11 & $9.491 \mathrm{e}+00$ & 10 \\
\hline 12 & $7.574 \mathrm{e}+00$ & 9 \\
\hline 13 & $8.848 \mathrm{e}+00$ & 9 \\
\hline 14 & $7.137 \mathrm{e}+00$ & 9 \\
\hline 15 & $5.986 \mathrm{e}+00$ & 8 \\
\hline 16 & $7.823 e+100$ & 9 \\
\hline 17 & $5.497 \mathrm{e}+100$ & 7 \\
\hline 18 & $4.555 e+110$ & 7 \\
\hline 19 & $2.681 \mathrm{e}+100$ & 4 \\
\hline 20 & $3.586 e+90$ & 6 \\
\hline 21 & $6.74(0 \mathrm{e}+0)$ & 8 \\
\hline 22 & $6.381 \mathrm{e}+(40$ & 8 \\
\hline 23 & $2.485 \mathrm{e}+00$ & 4 \\
\hline 24 & $1.040 \mathrm{e}+01$ & 10 \\
\hline 25 & $5.138 \mathrm{e}+1 \mathrm{M})$ & 7 \\
\hline 26 & $8.701 \mathrm{e}+00$ & 9 \\
\hline 27 & $3.158 \mathrm{e}+(0)$ & 5 \\
\hline 28 & $4.475 \mathrm{e}+00$ & 7 \\
\hline 29 & $4.282 \mathrm{e}+(00$ & 6 \\
\hline 30 & $2.174 \mathrm{e}+(1)$ & 3 \\
\hline 31 & $3.549 \mathrm{e}+100$ & 6 \\
\hline 32 & $6.018 \mathrm{e}+(0)$ & 8 \\
\hline 33 & $8.041 \mathrm{e}+190$ & 9 \\
\hline 34 & $4.029 \mathrm{e}+00$ & 6 \\
\hline 35 & $1.364 e+01$ & 11 \\
\hline
\end{tabular}




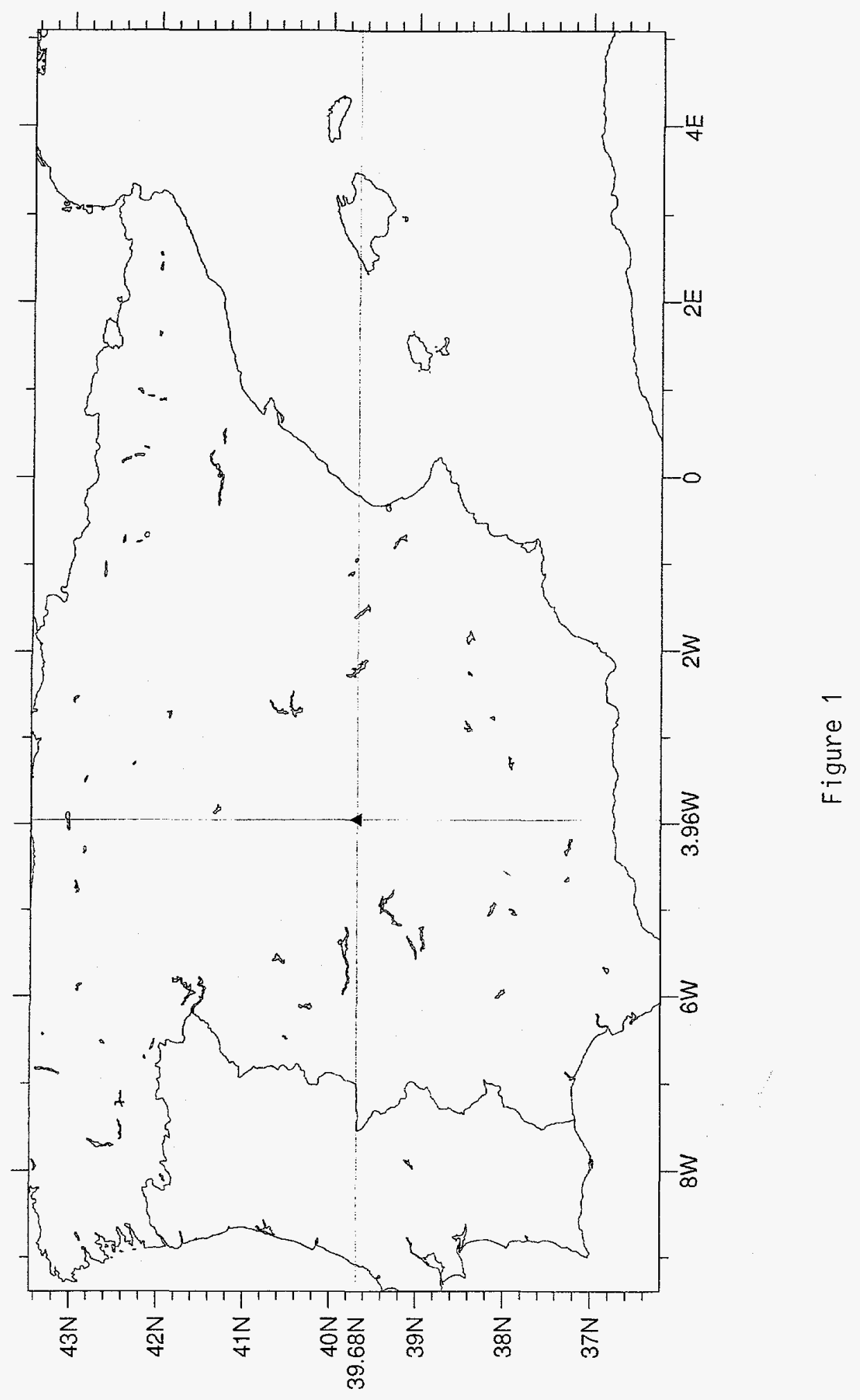




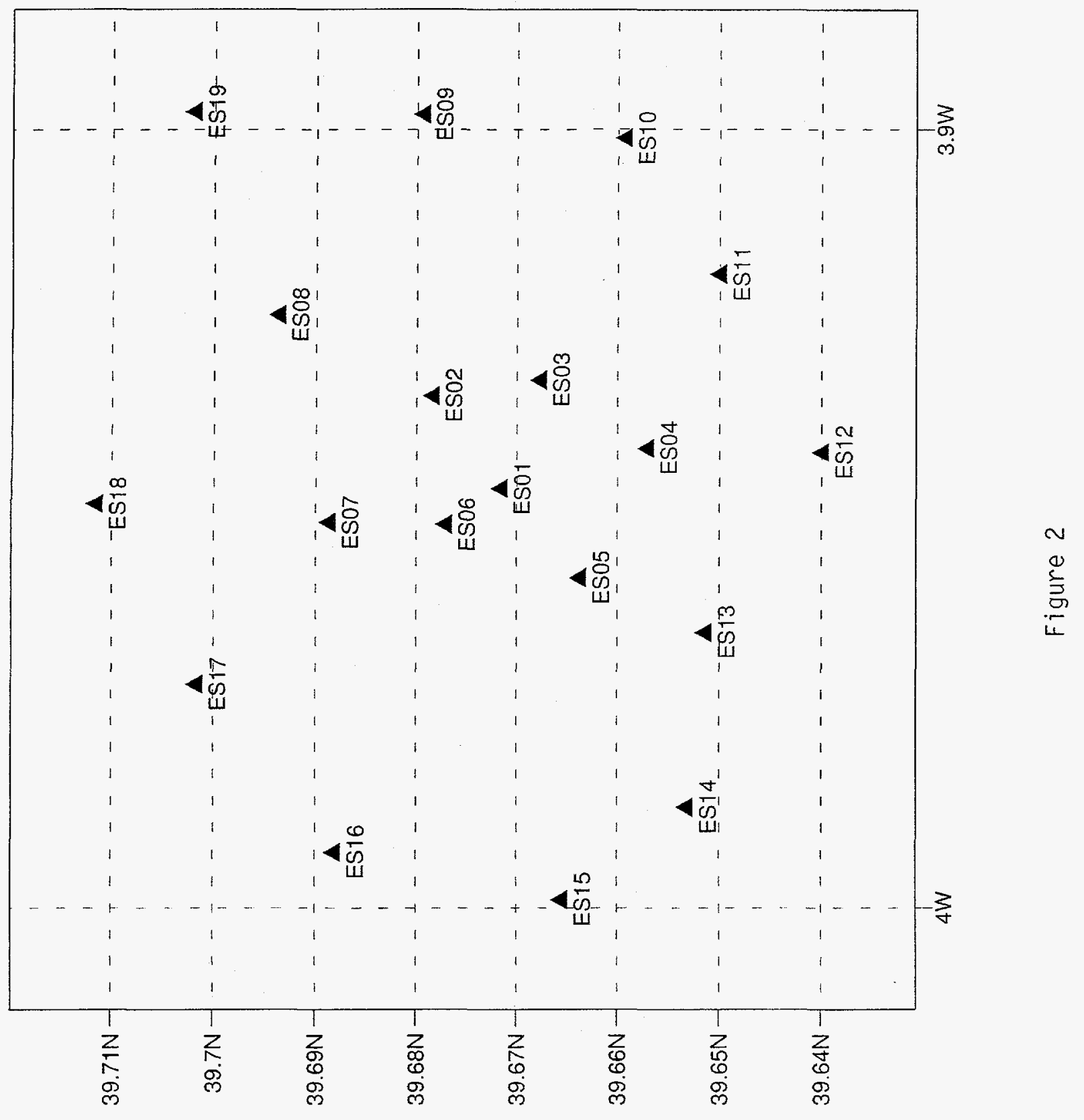




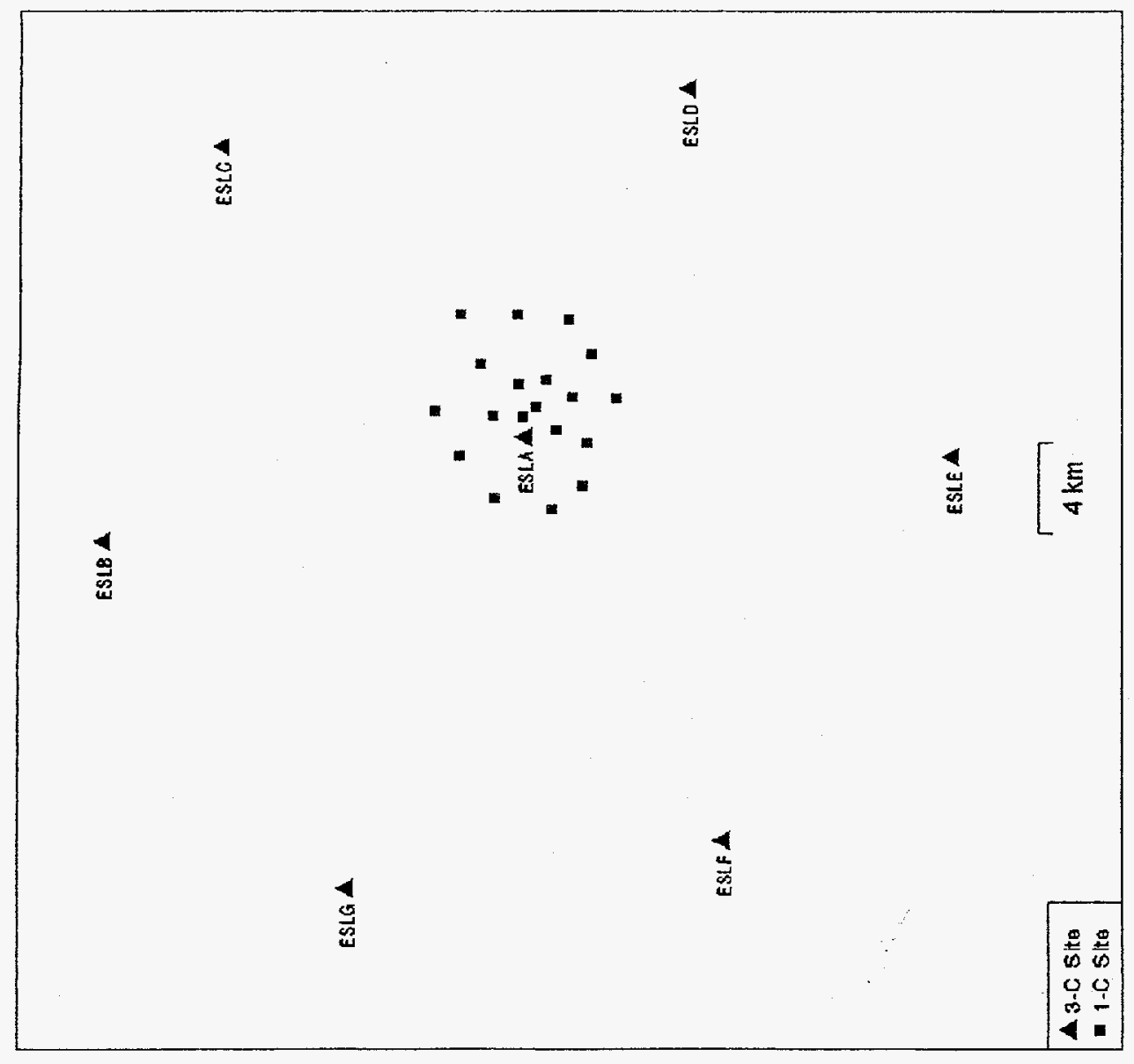

$m$
0
$\frac{5}{5}$
$\frac{\pi}{4}$ 


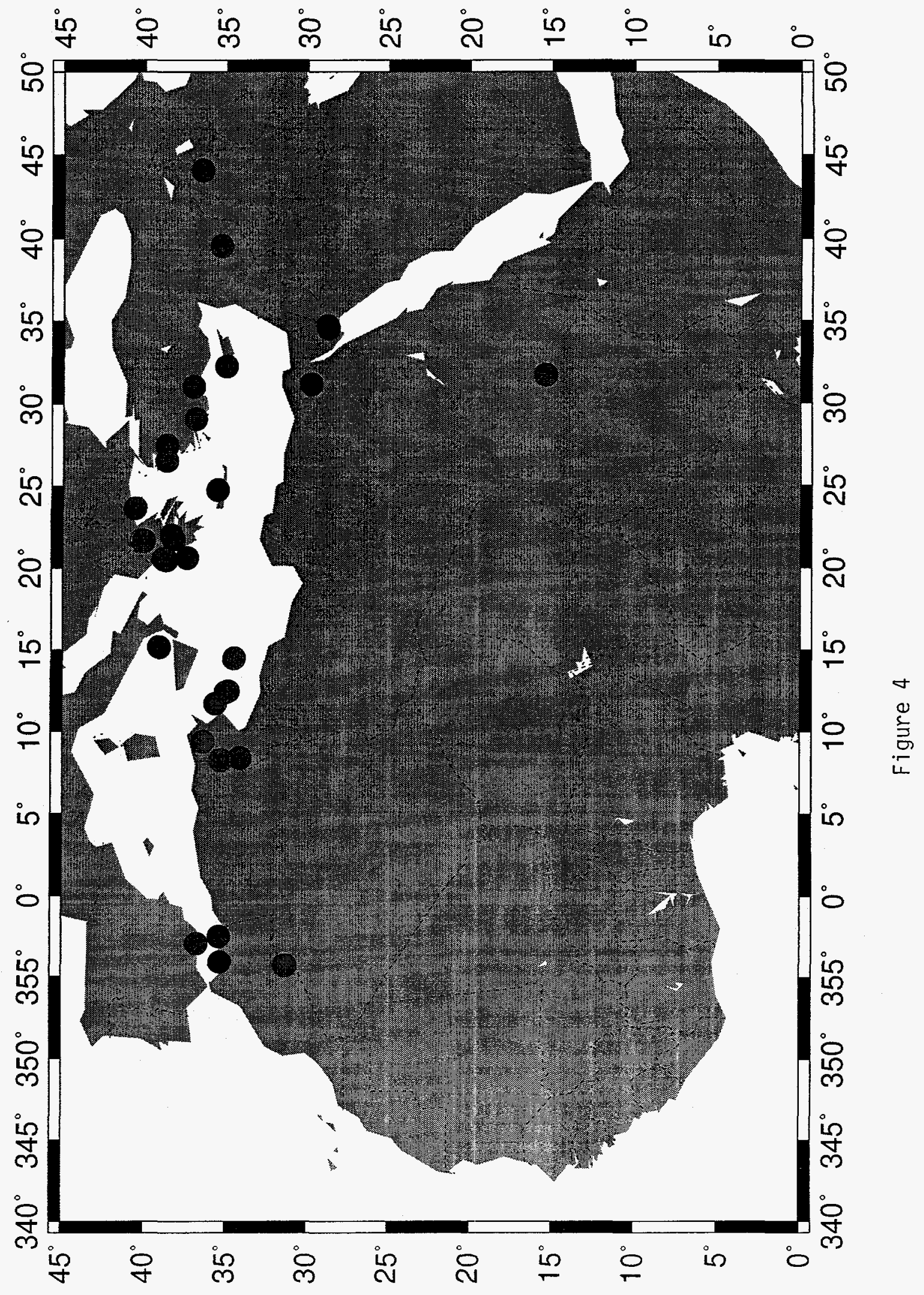


Histograms
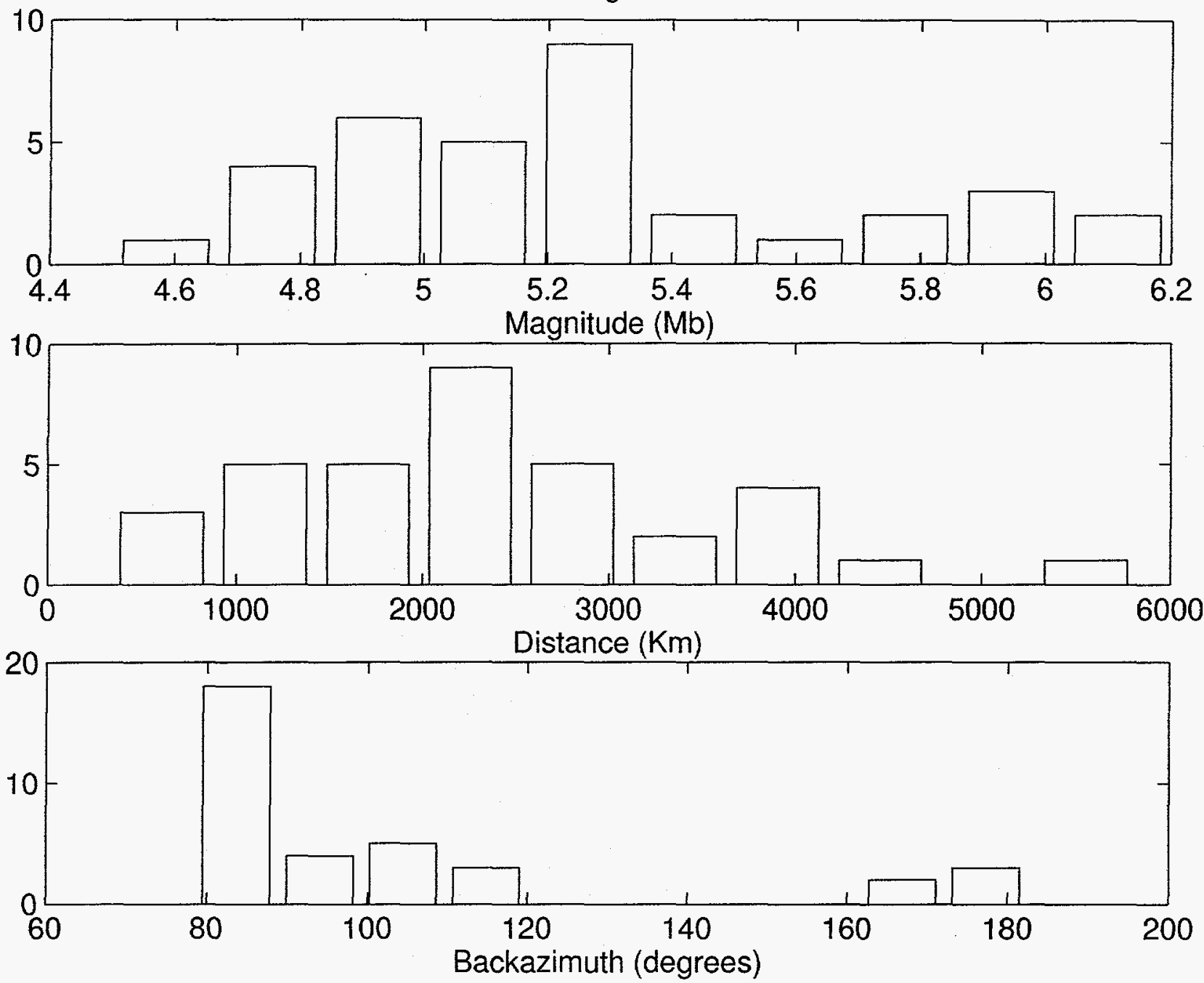

Figure 5 


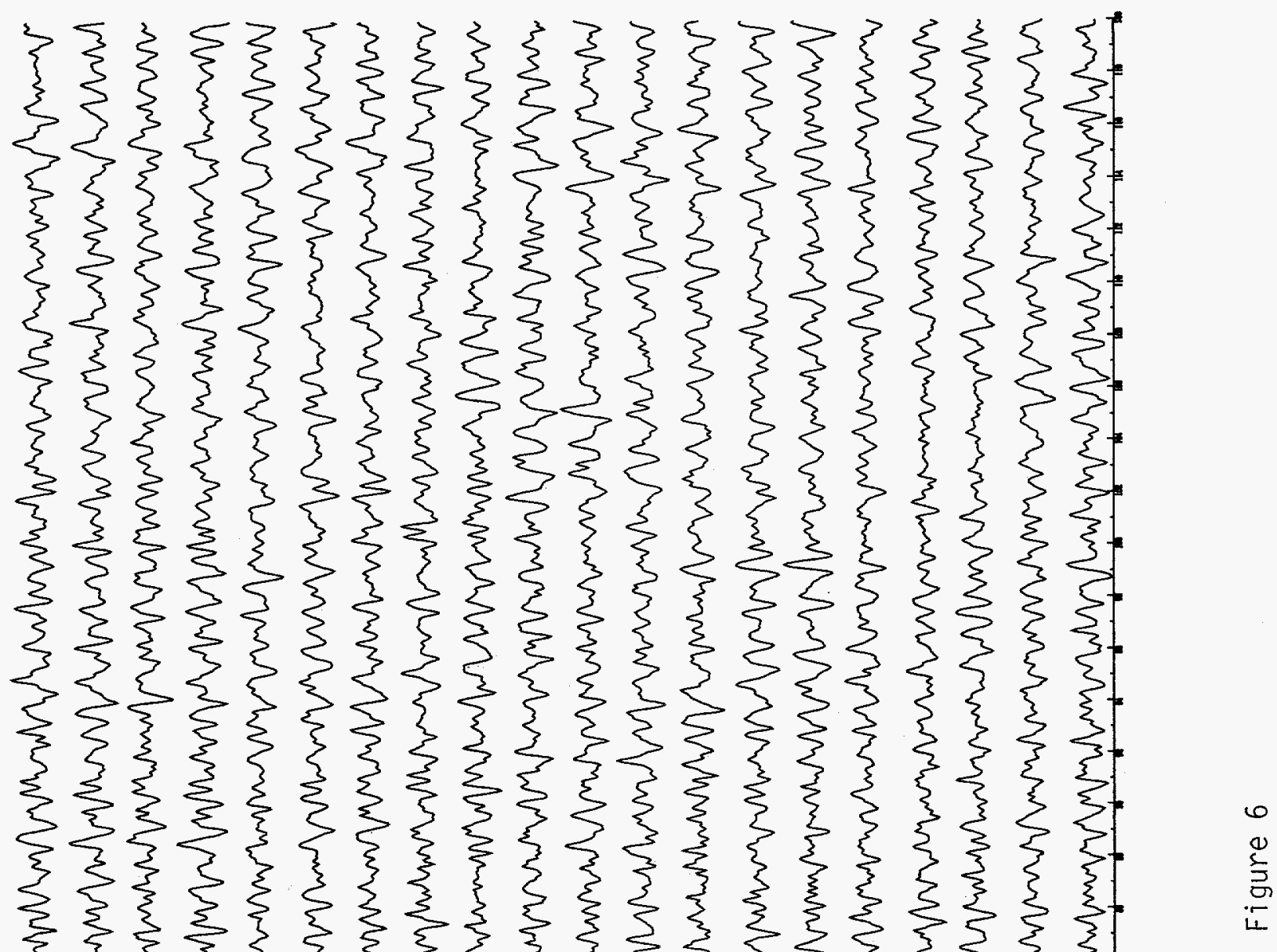




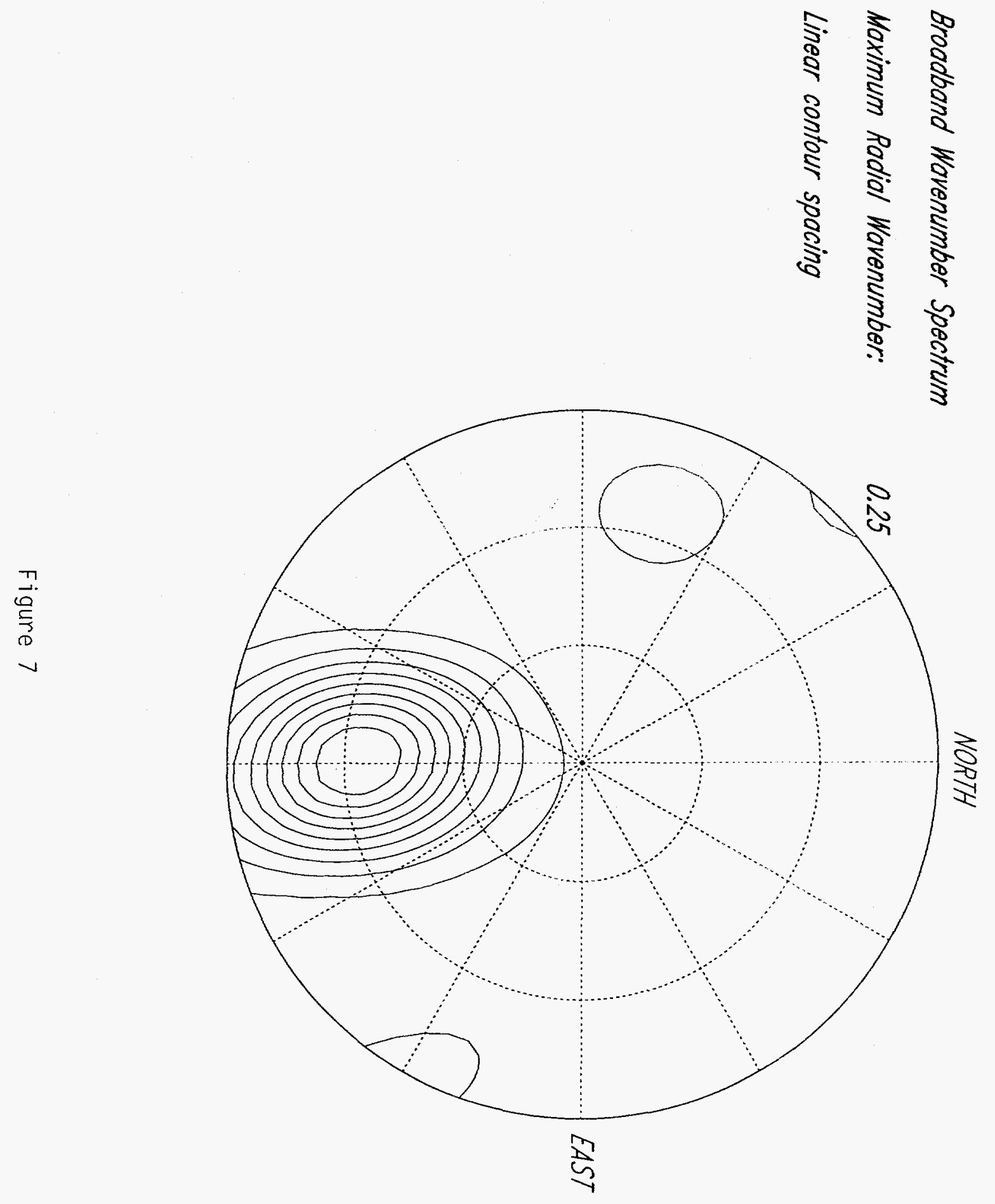


Broadband Bearing Error for $1-2 \mathrm{~Hz}$
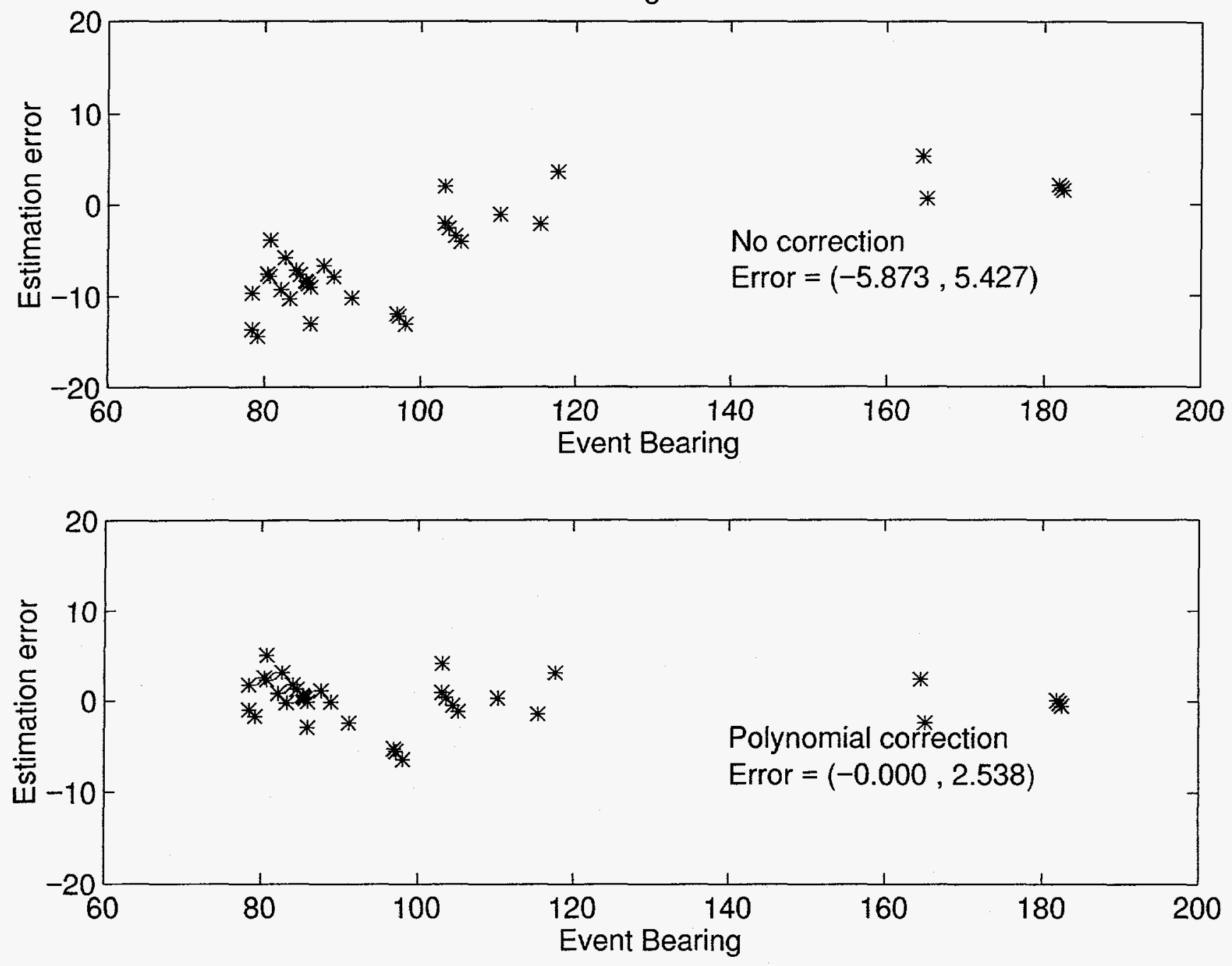

Figure 8-a 
Broadband Bearing Error for $2-3 \mathrm{~Hz}$
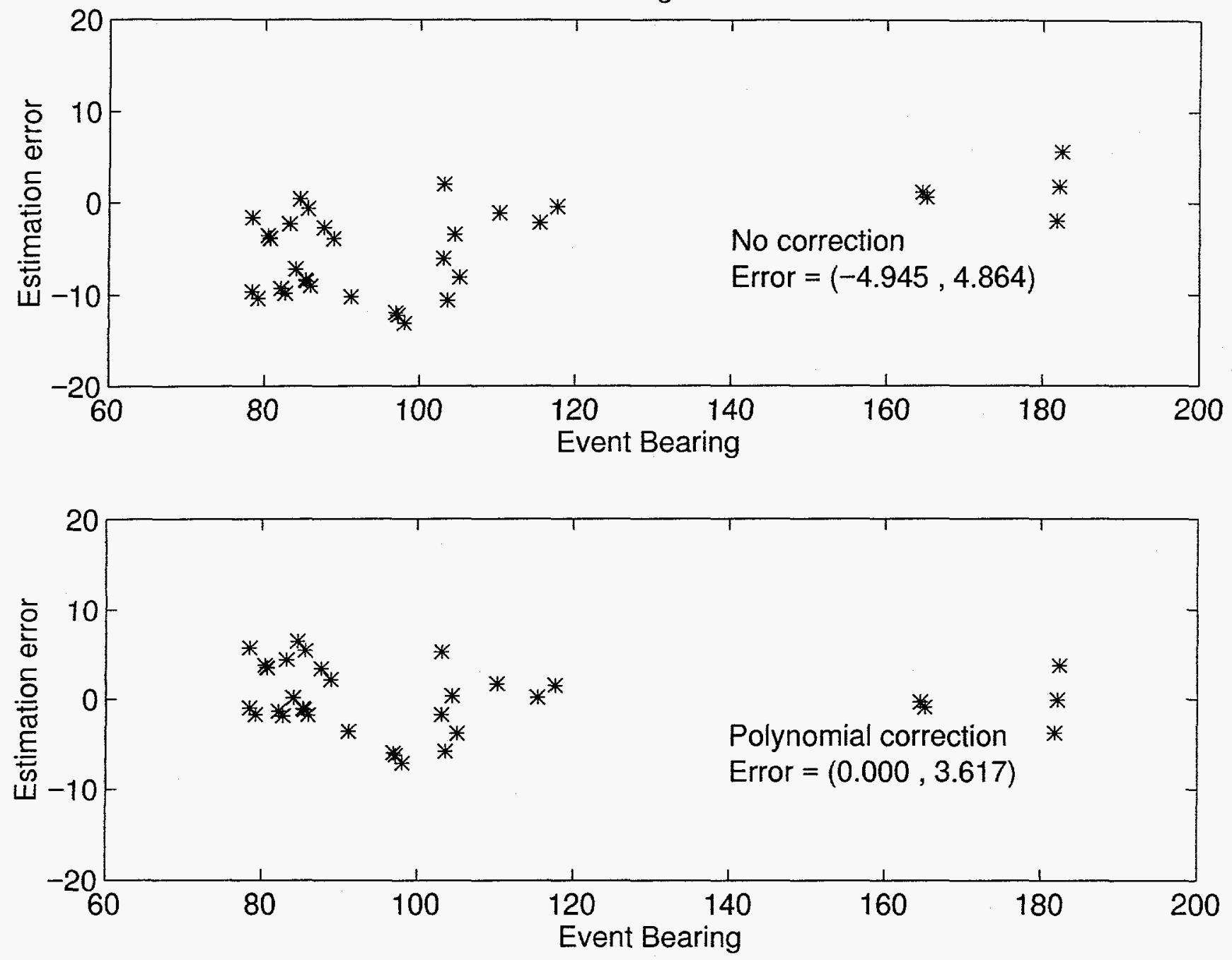

Figure 8-b 

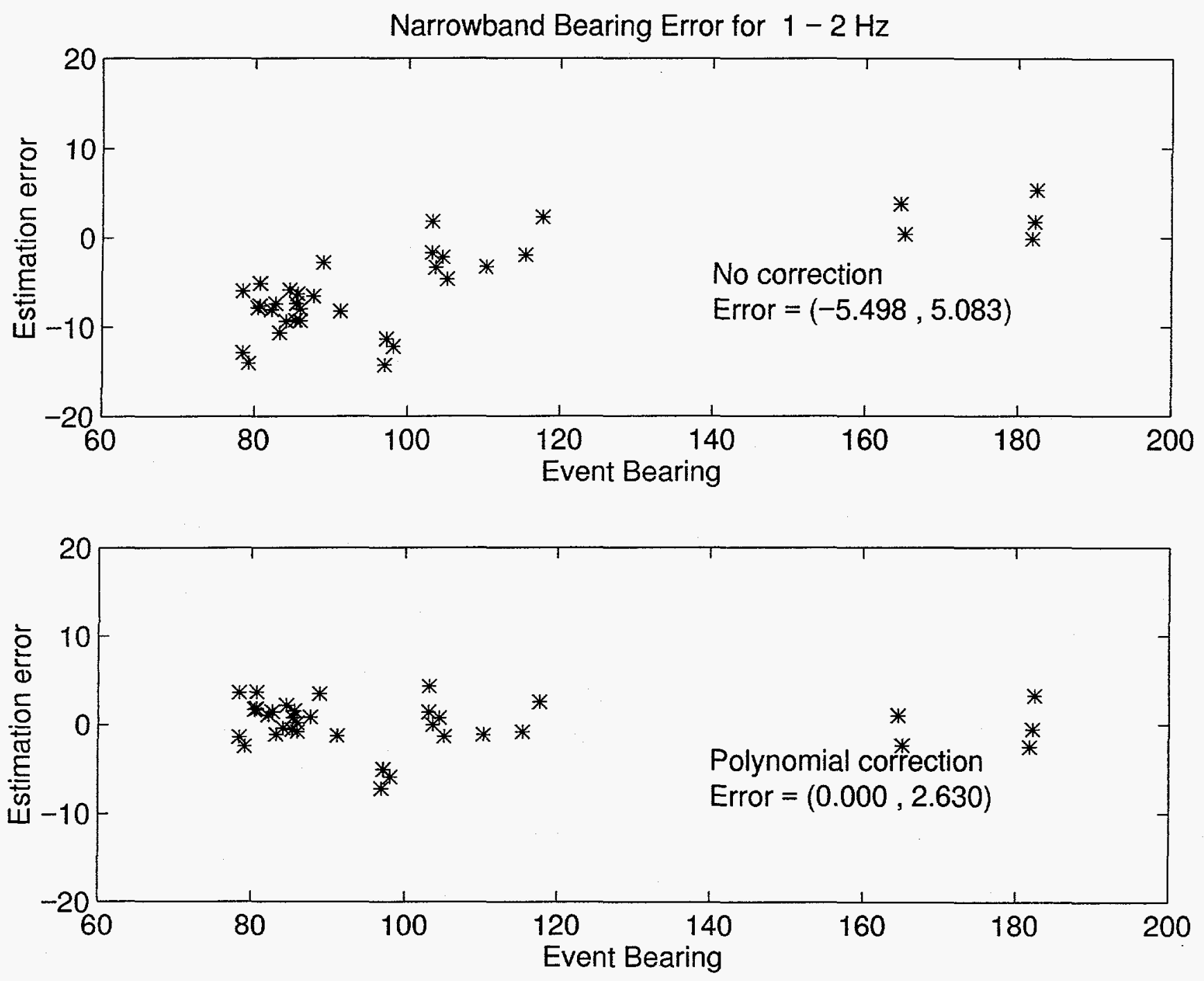

Figure 9-a 

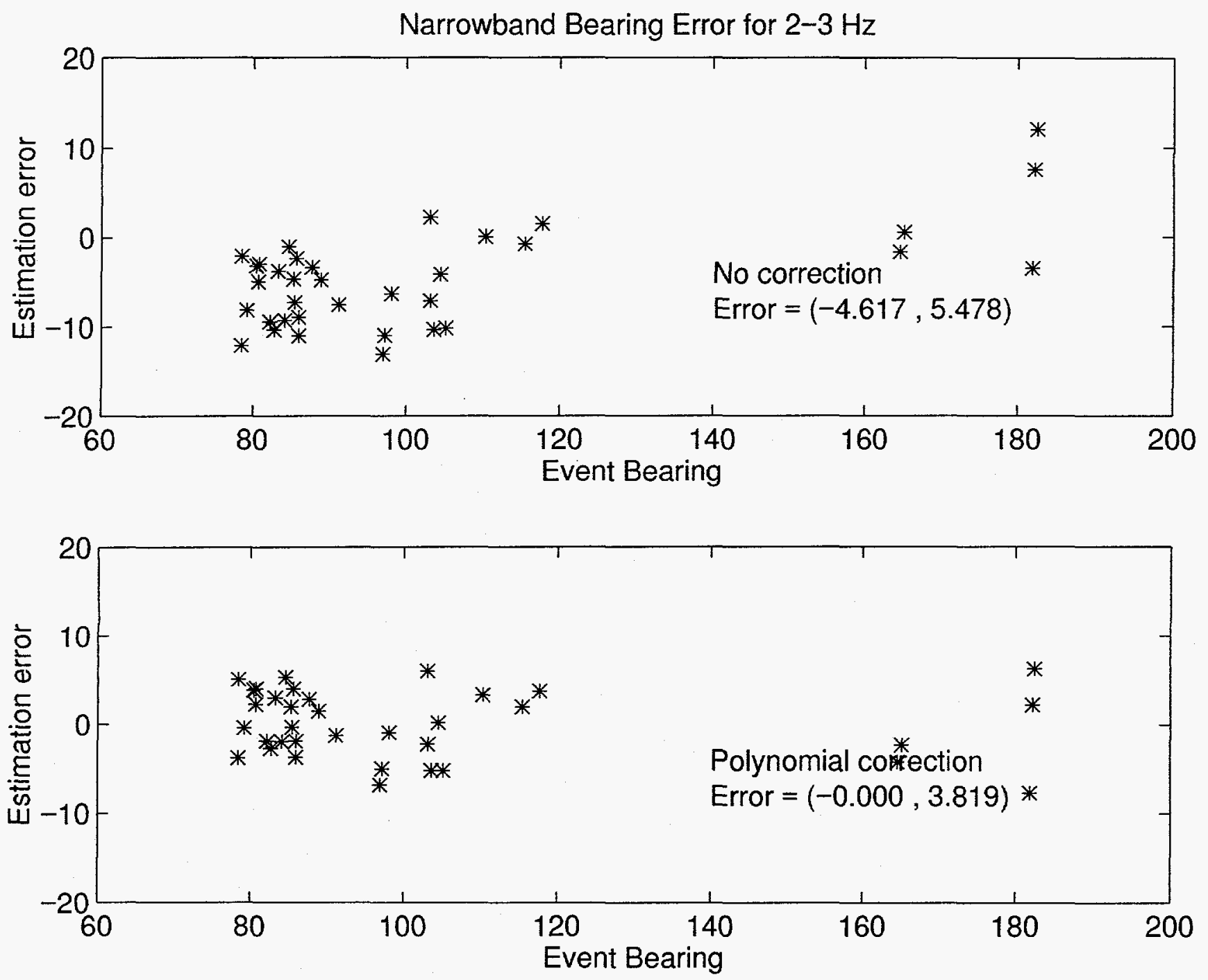

Figure 9-b 


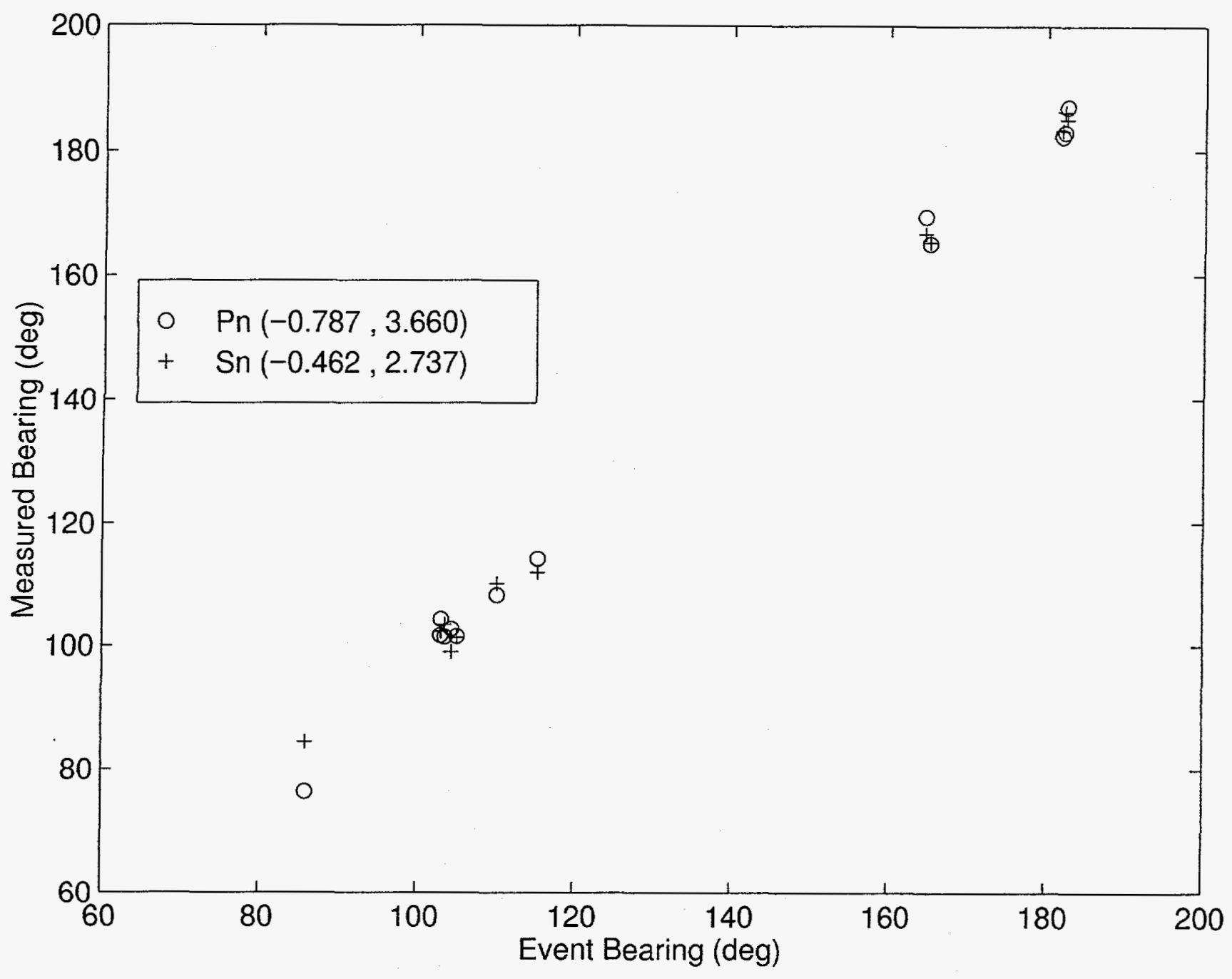

Figure 10 


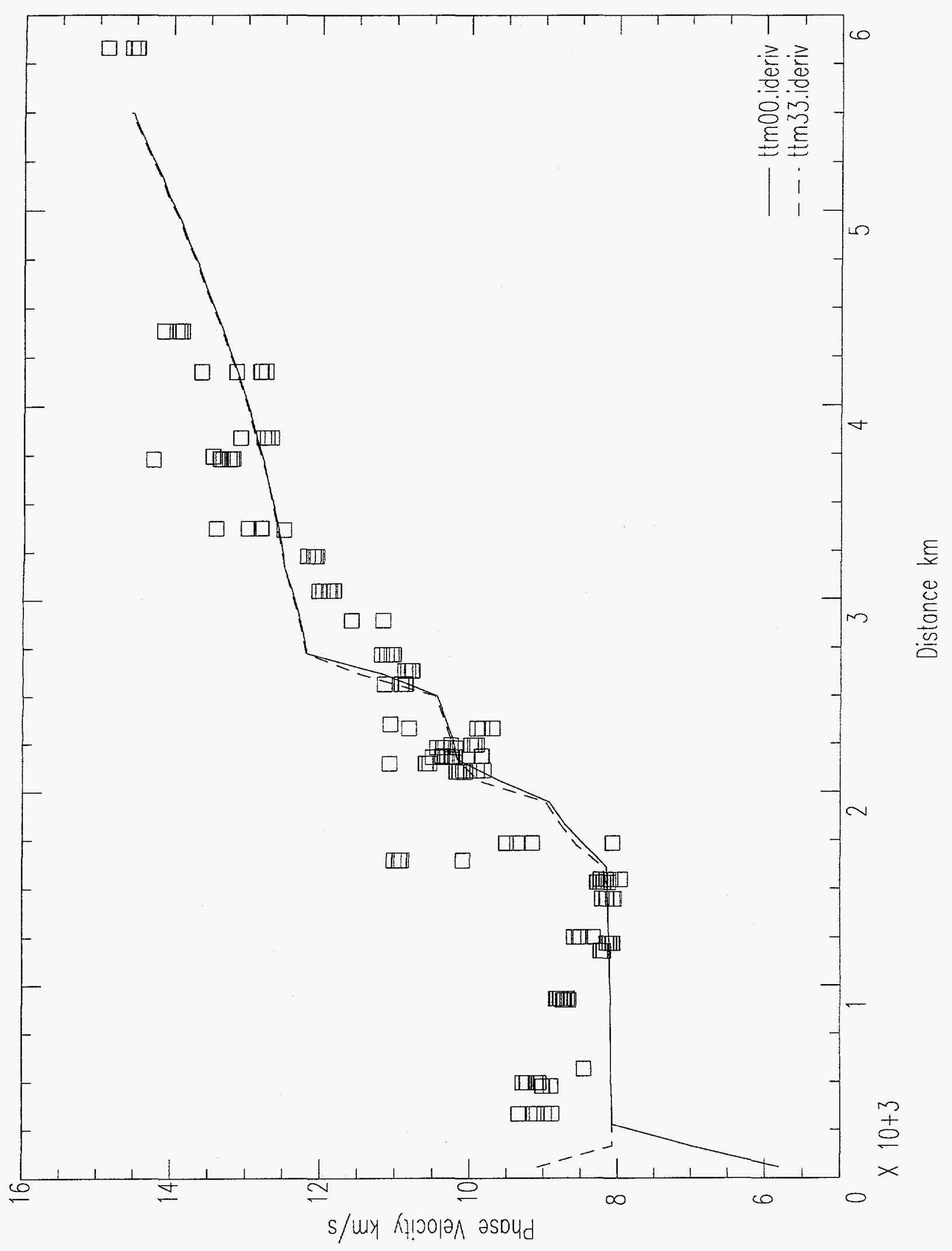

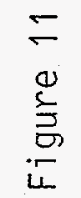




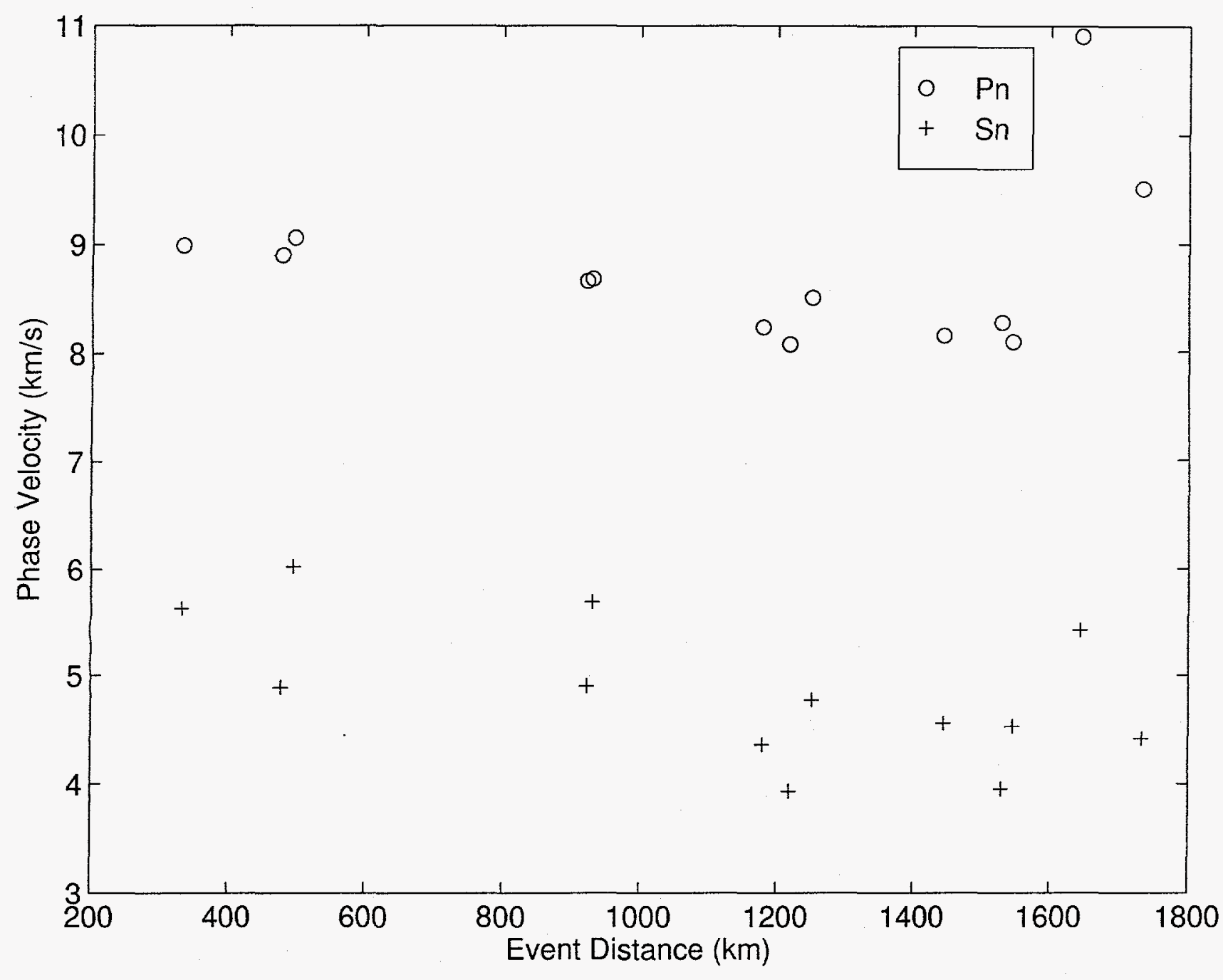

Figure 12 

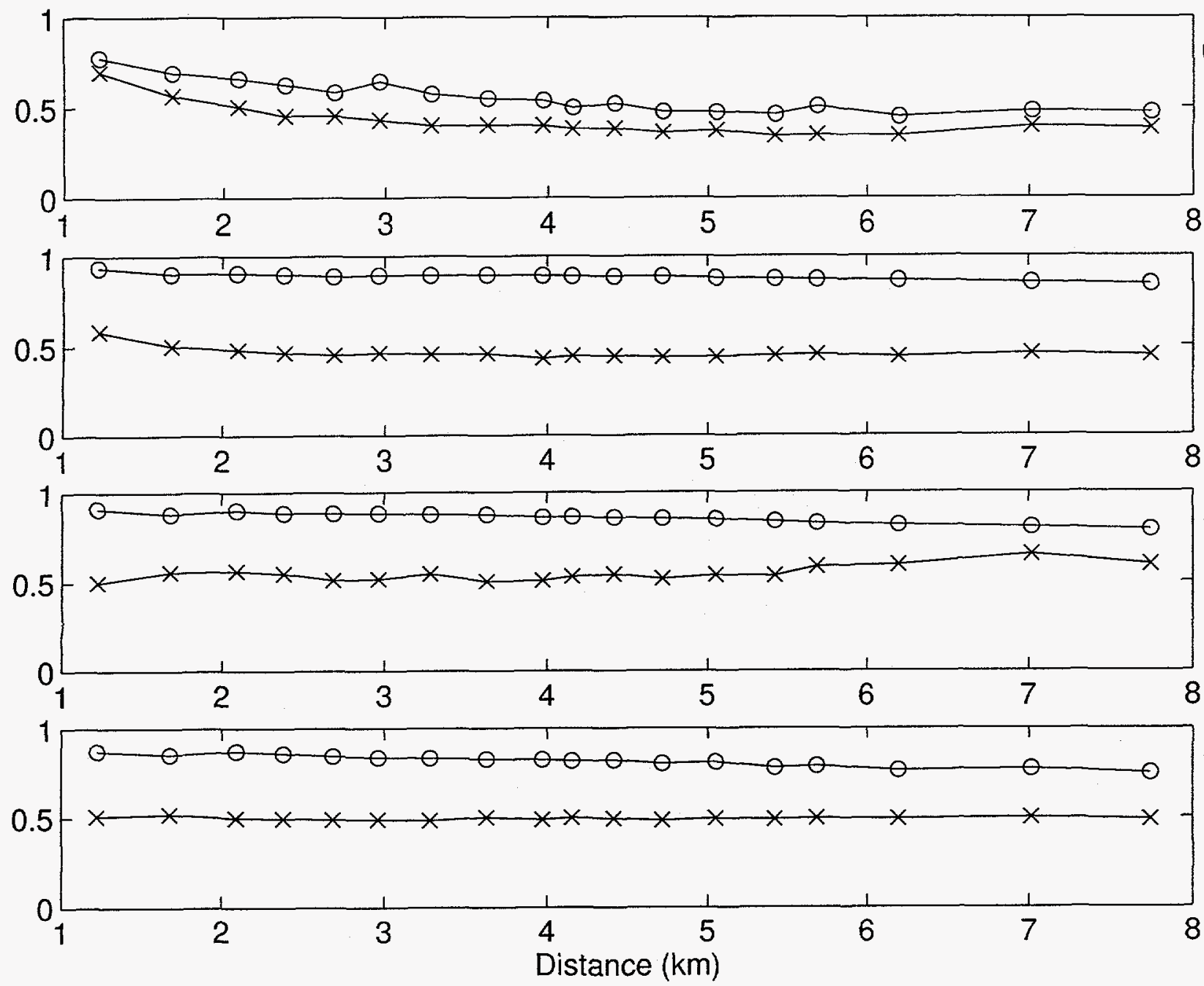

$1.50 \mathrm{~Hz}$

$1.75 \mathrm{~Hz}$

Figure 13-a 

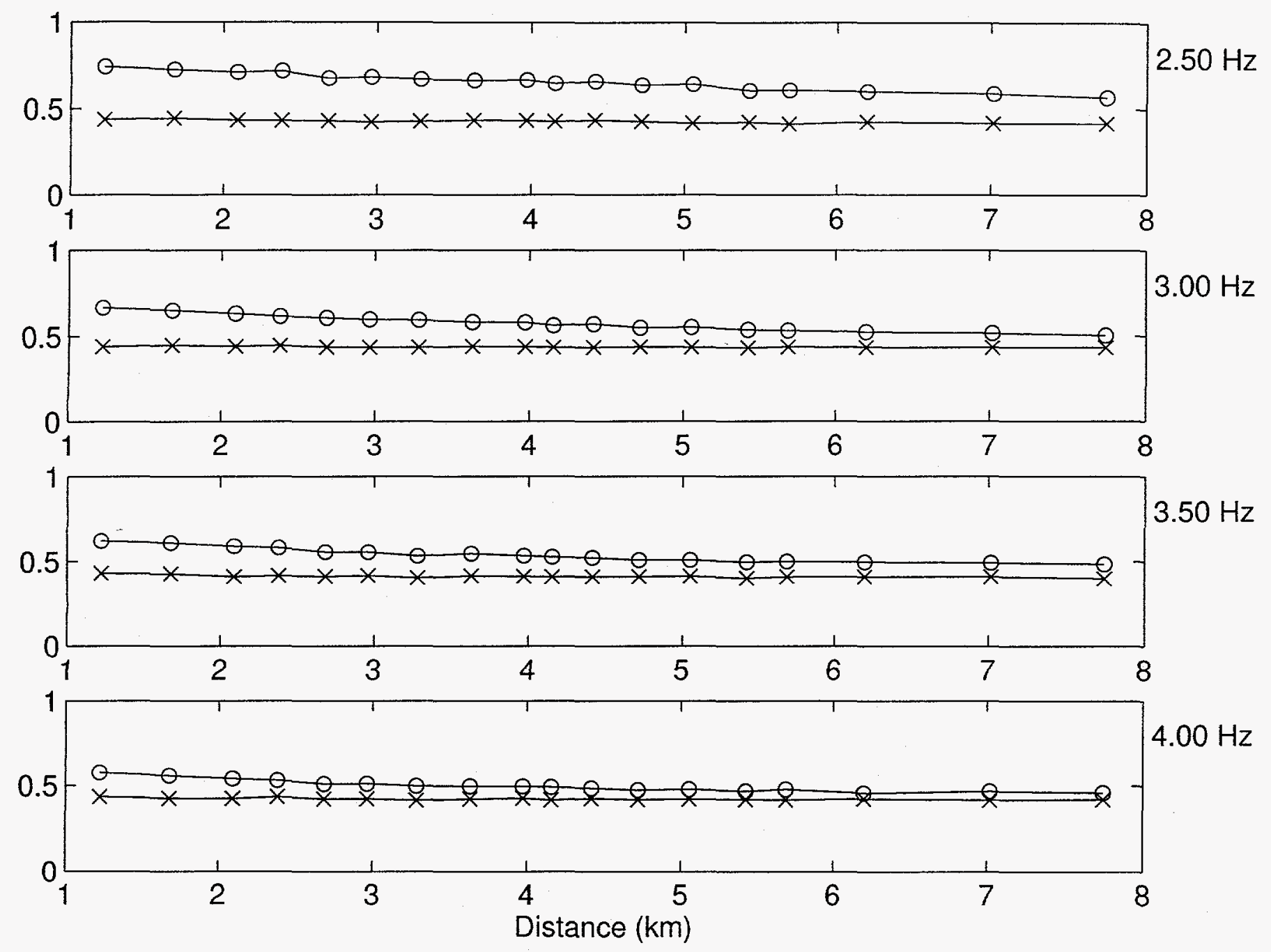

Figure 13-b 

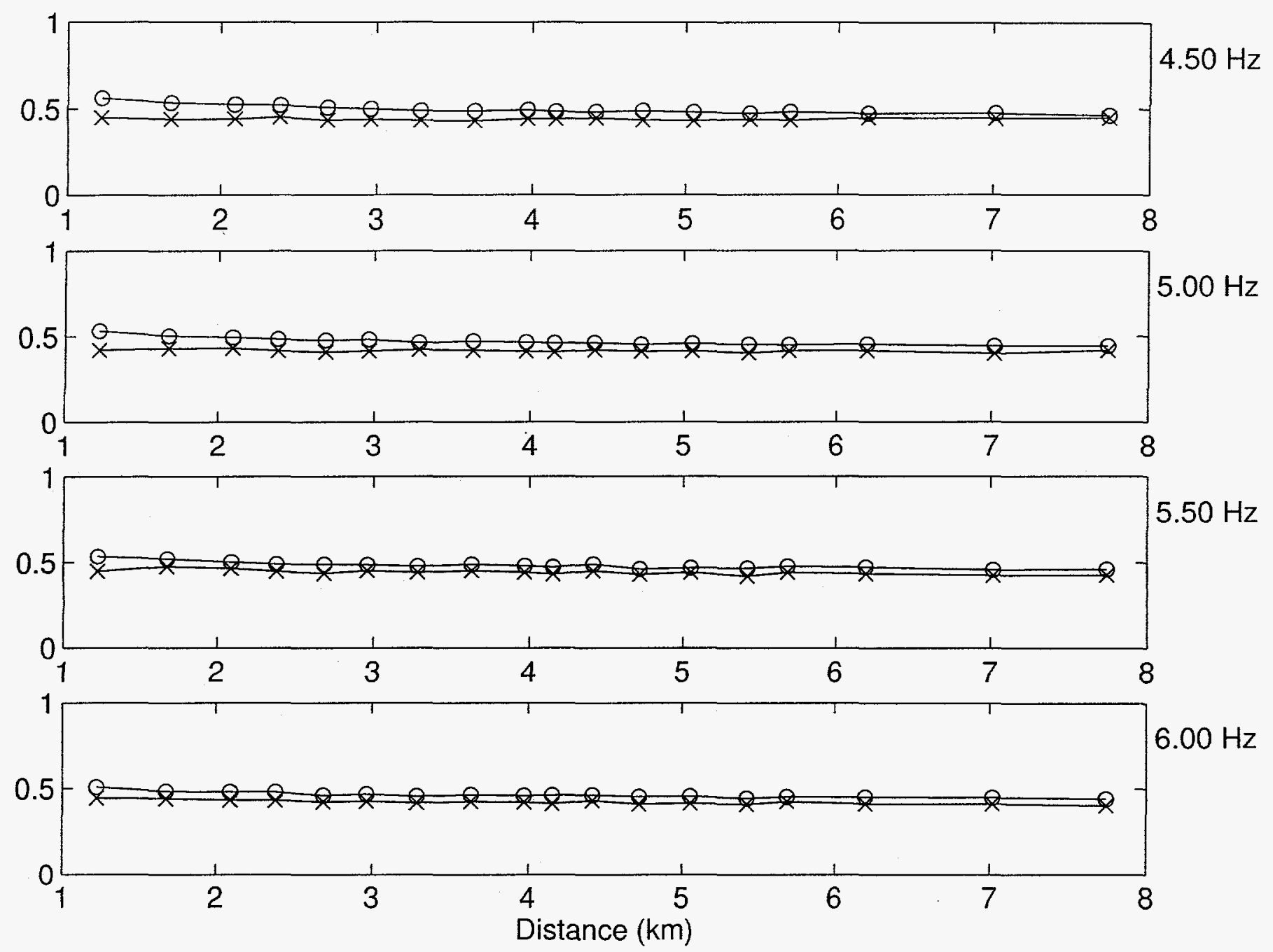

Figure 13-c 

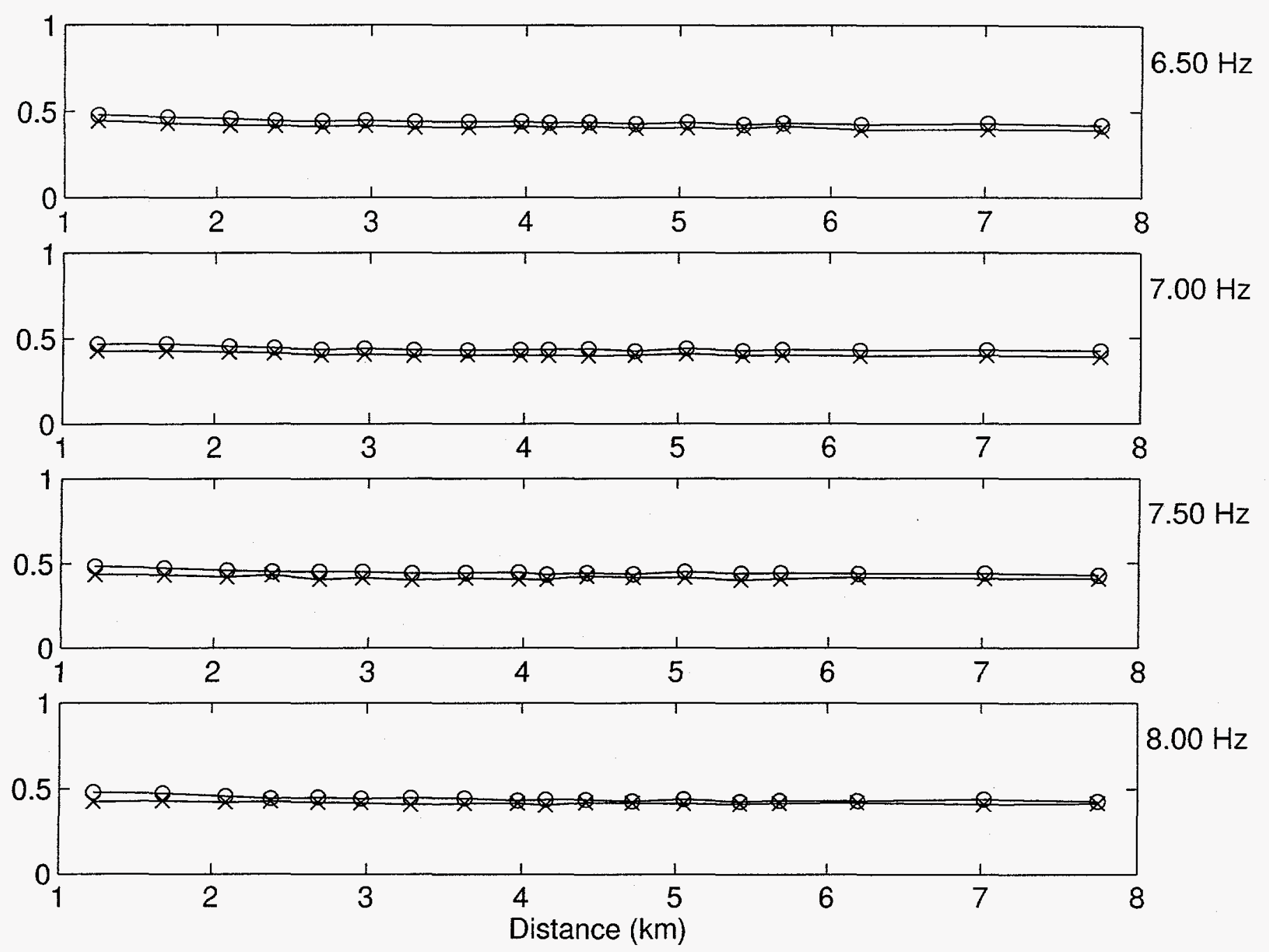

Figure 13-d 


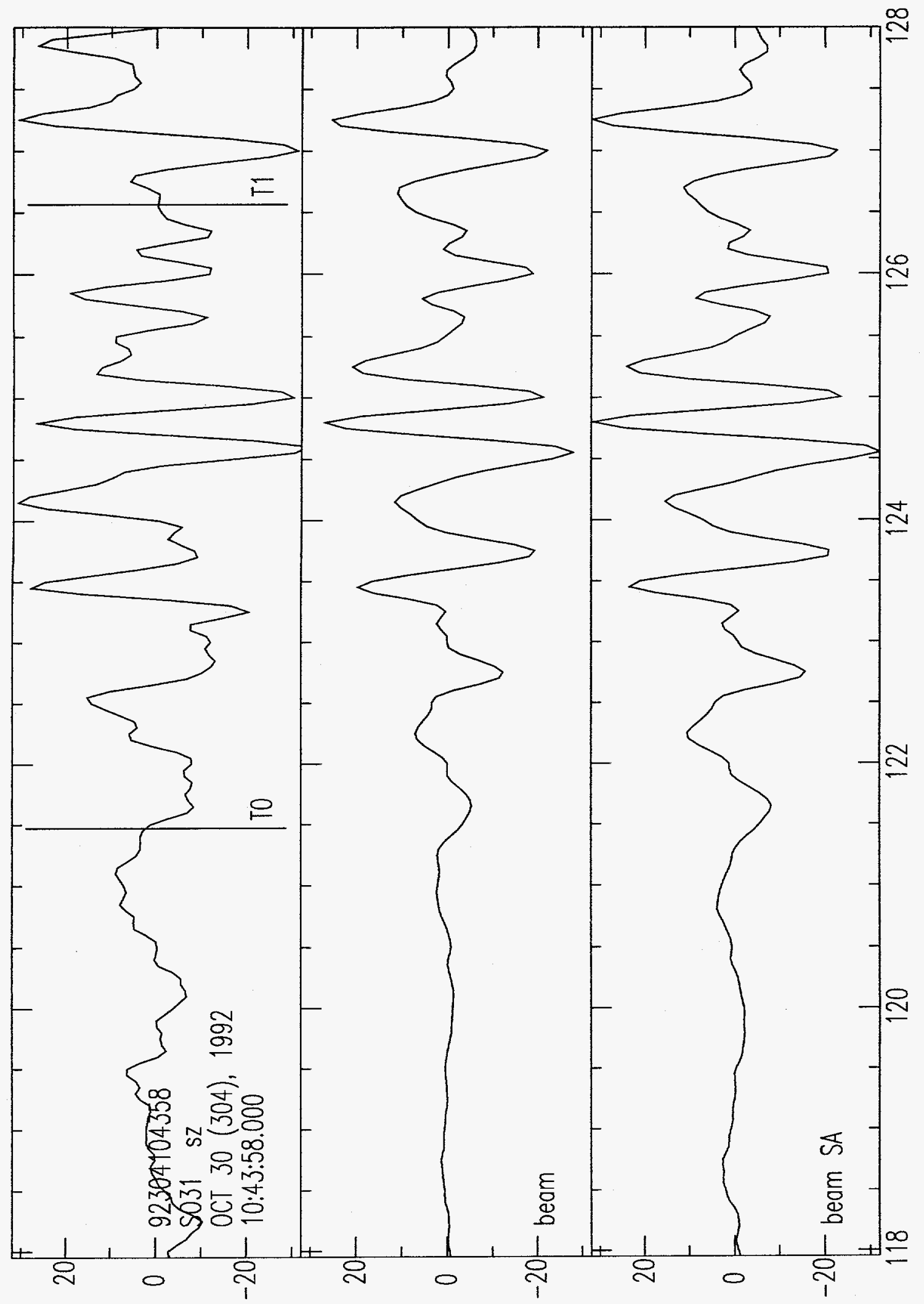

\pm
$\frac{5}{5}$
$\frac{5}{5}$ 
Beampattern at 180 degrees azimuth

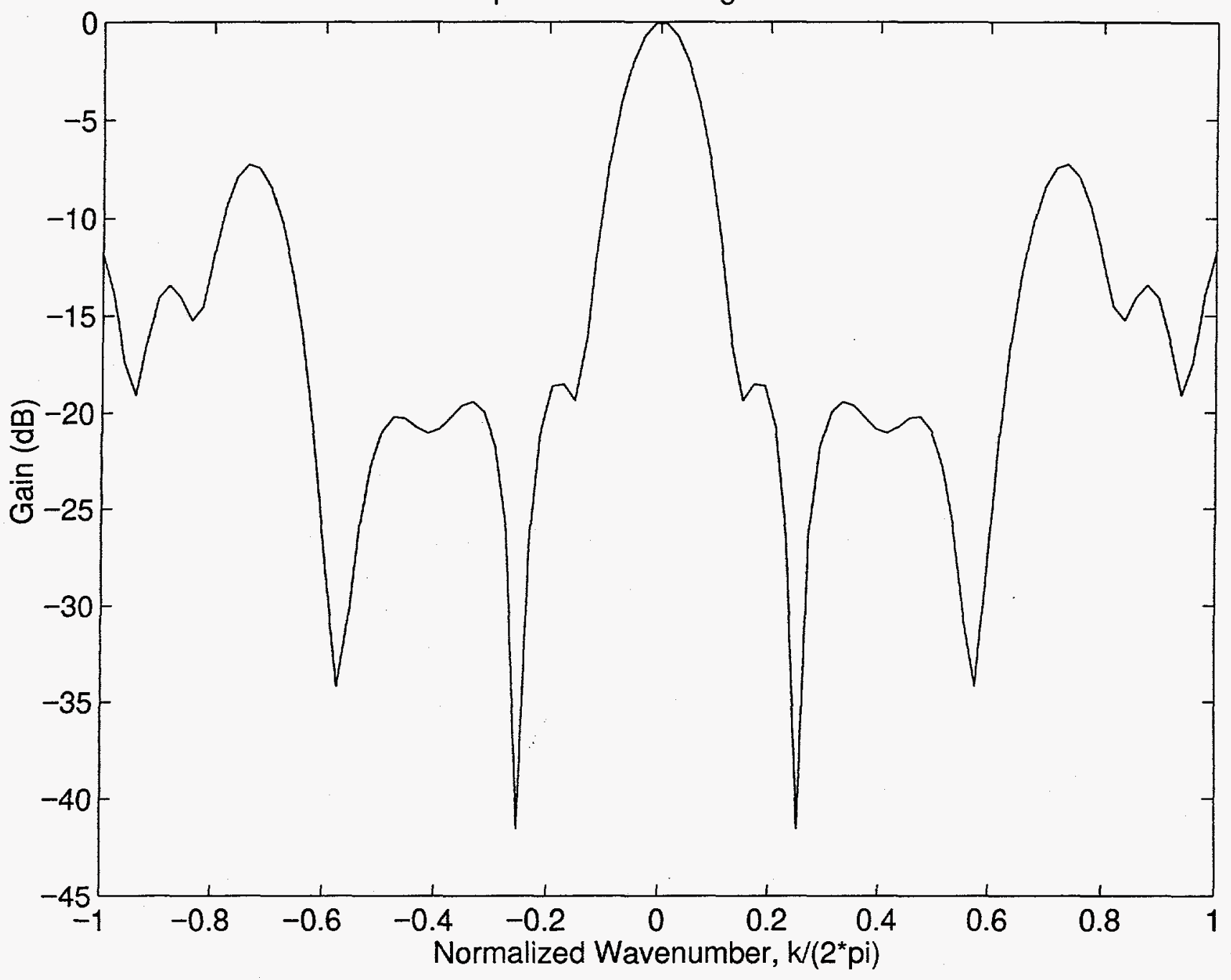

Figure 15 
Beampattern at 45 degrees azimuth

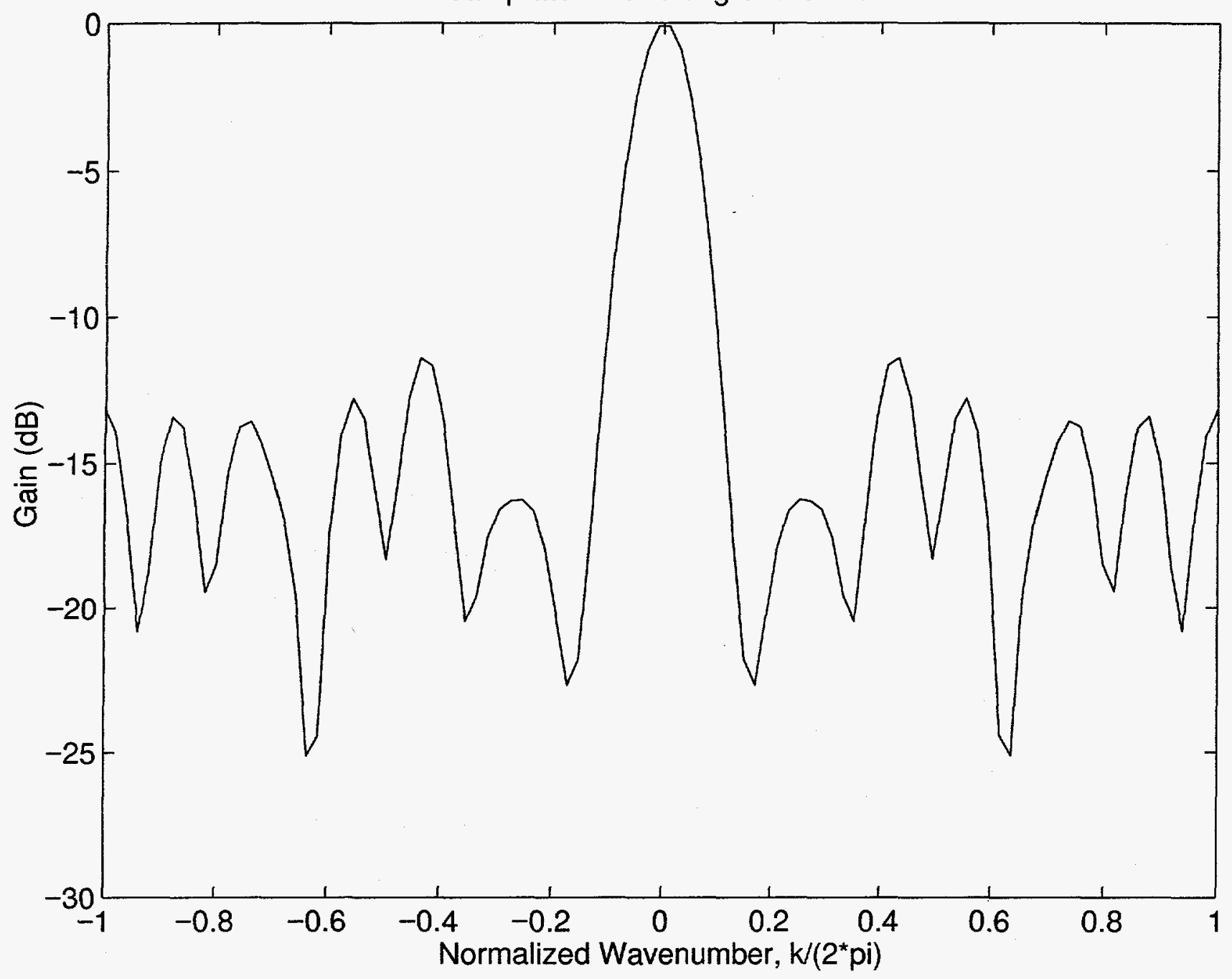

Figure 16 


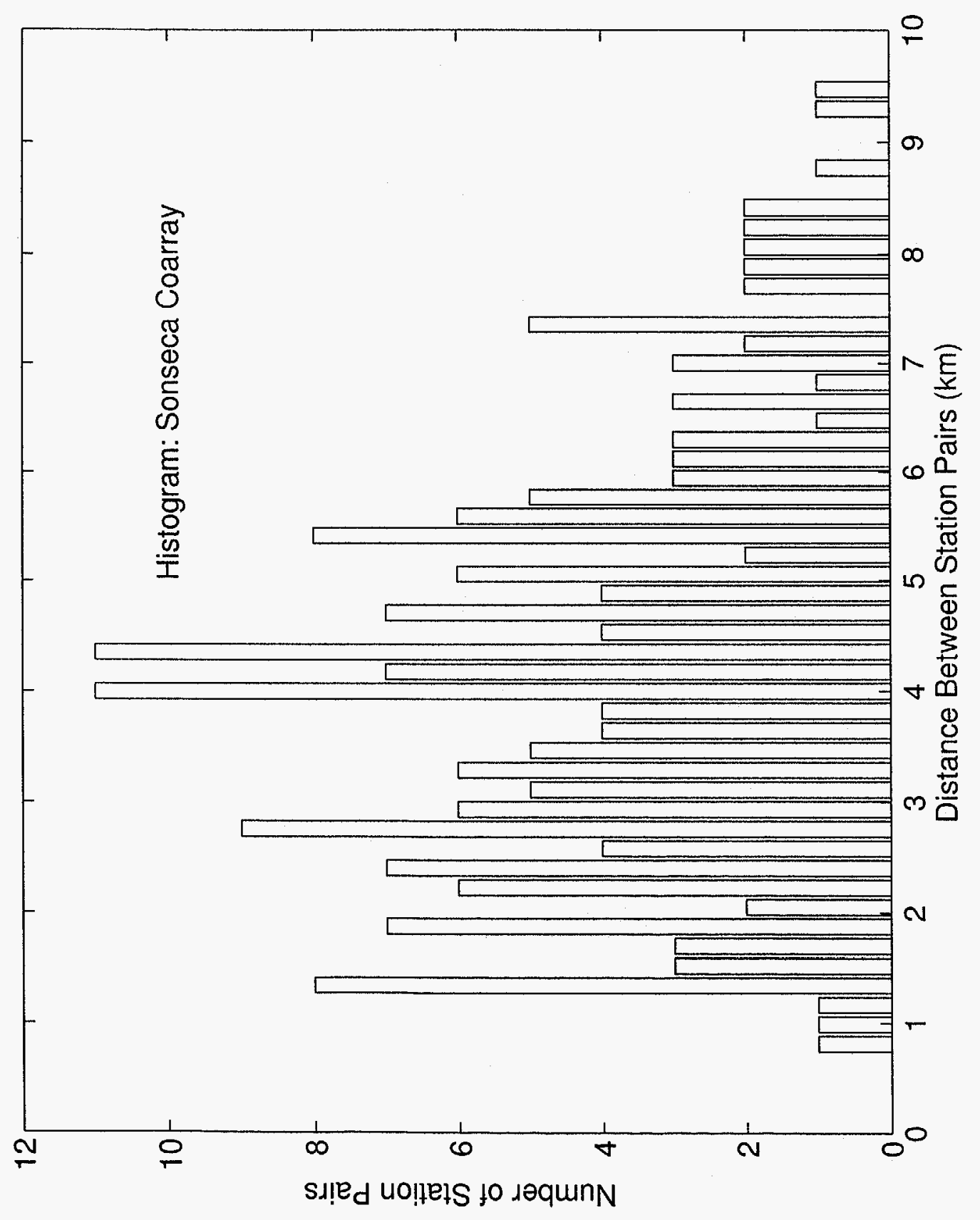




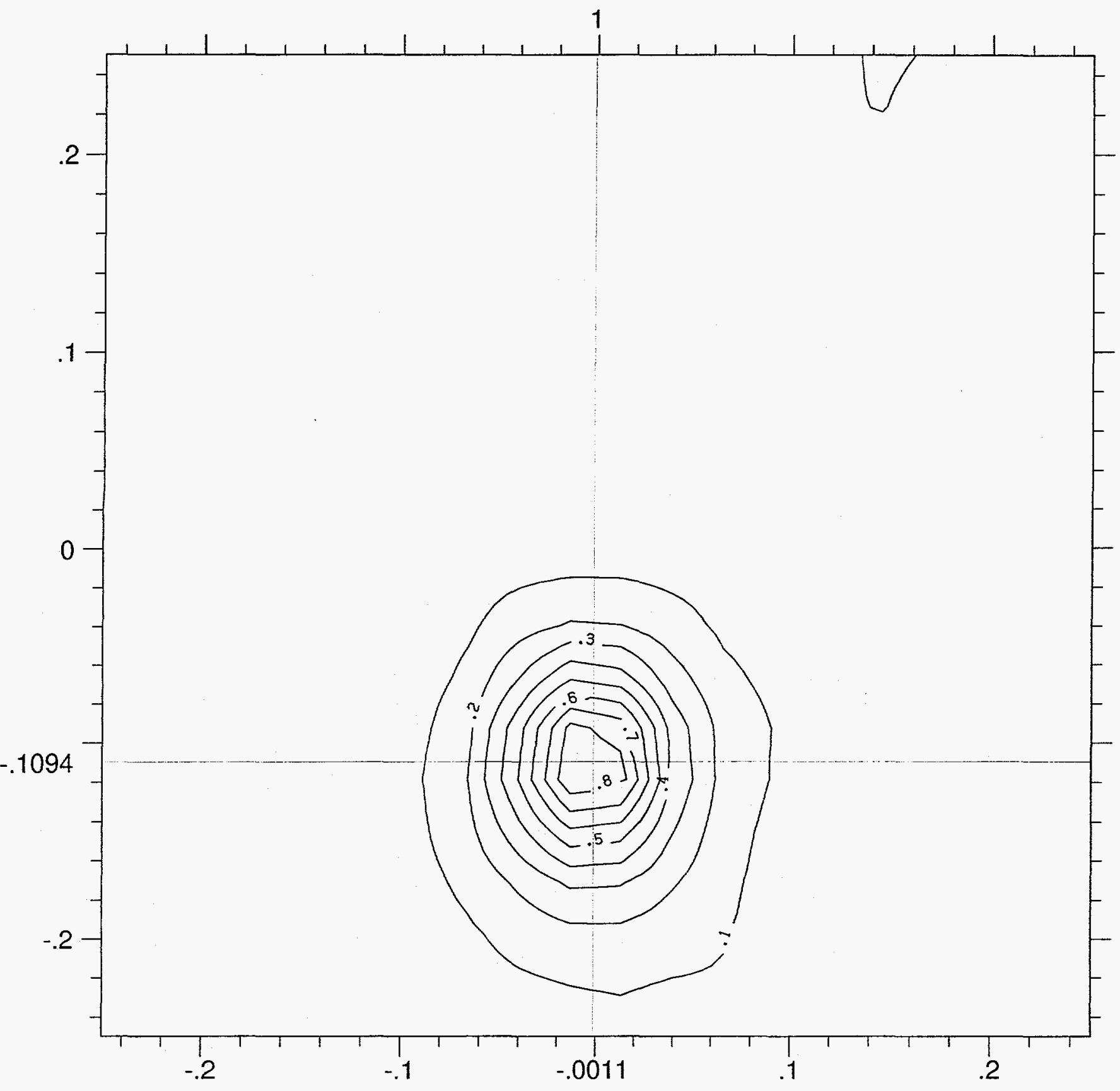

$\mathrm{Sx}(\mathrm{sec} / \mathrm{km})$

Figure 18-a 


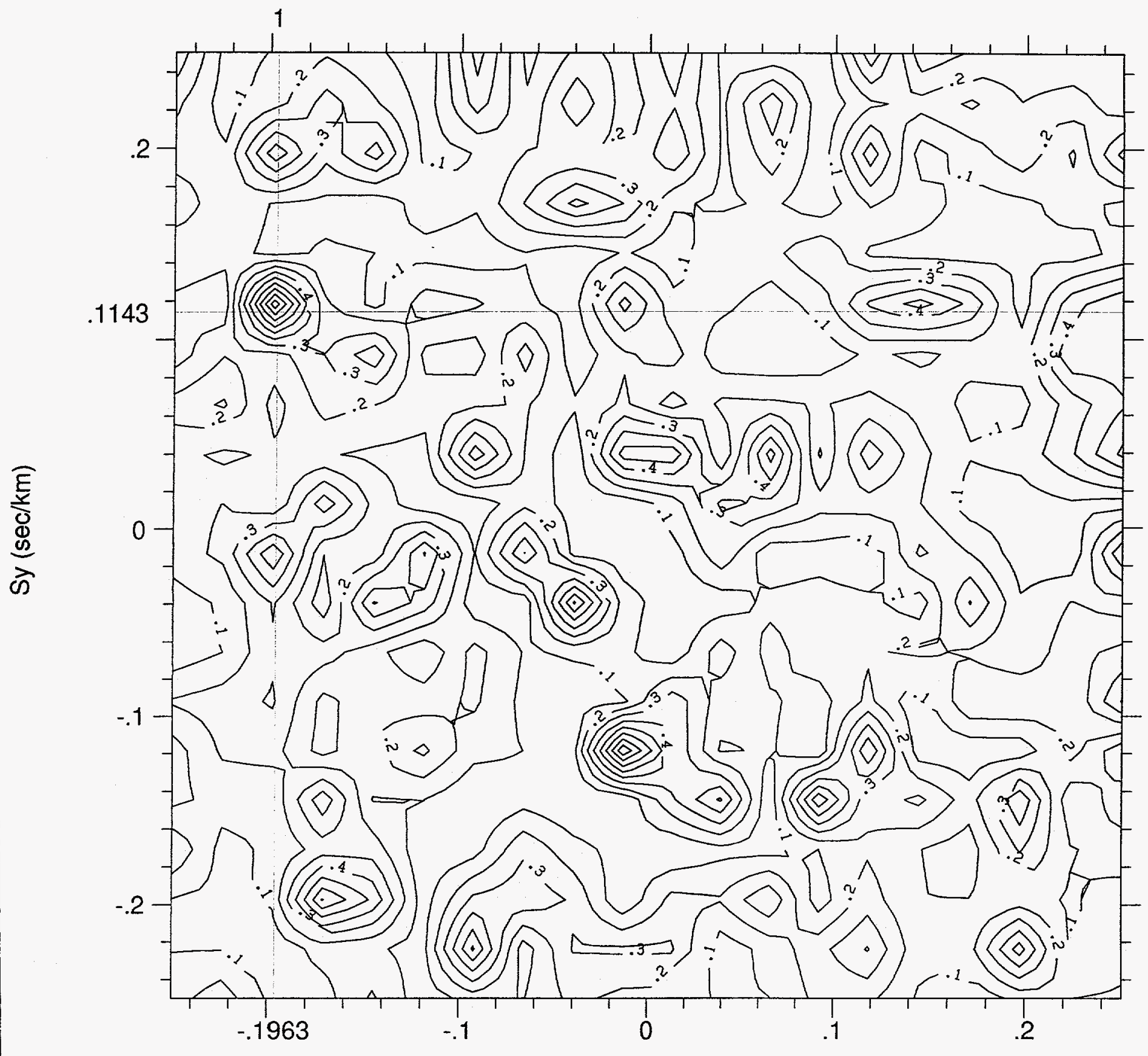

$\mathrm{Sx}(\mathrm{sec} / \mathrm{km})$

Figure 18-b 


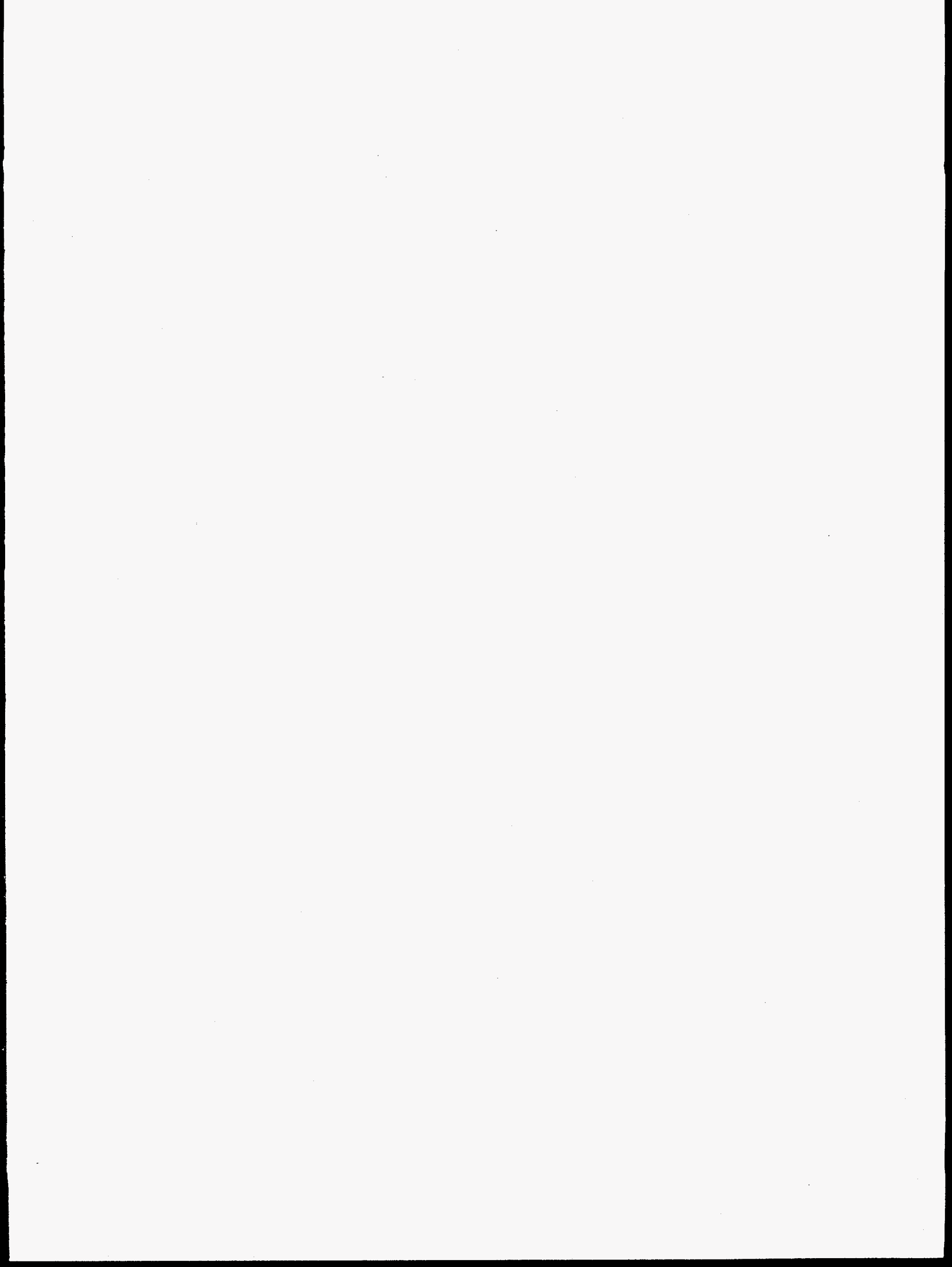

